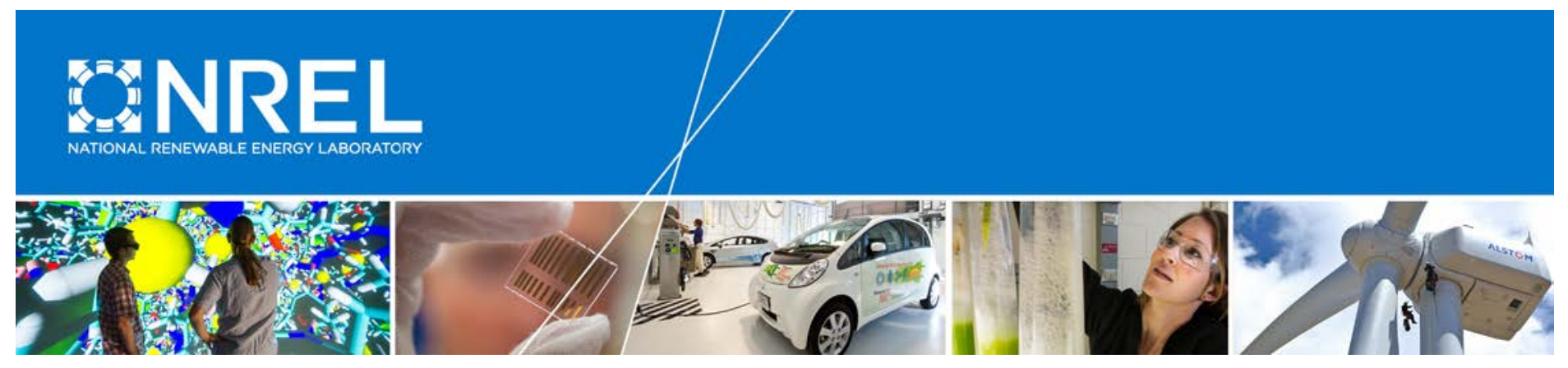

\title{
Annual Energy Savings and Thermal Comfort of Autonomously Heated and Cooled Office Chairs
}

Scott Carmichael, Chuck Booten, Joseph Robertson, Justin Chin, Dane Christensen, Jacquelyn Pless, and Doug Arent National Renewable Energy Laboratory (NREL)

NREL is a national laboratory of the U.S. Department of Energy Office of Energy Efficiency \& Renewable Energy Operated by the Alliance for Sustainable Energy, LLC

This report is available at no cost from the National Renewable Energy Laboratory (NREL) at www.nrel.gov/publications.

Technical Report

NREL/TP-6A80-66431

July 2016

Contract No. DE-AC36-08G028308 


\section{Annual Energy Savings and Thermal Comfort of Autonomously Heated and Cooled Office Chairs}

Scott Carmichael, Chuck Booten, Joseph Robertson, Justin Chin, Dane Christensen, Jacquelyn Pless, and Doug Arent National Renewable Energy Laboratory (NREL)

Prepared under Task No. BE4R.3071
National Renewable Energy Laboratory 15013 Denver West Parkway Golden, CO 80401

303-275-3000 • www.nrel.gov
NREL is a national laboratory of the U.S. Department of Energy Office of Energy Efficiency \& Renewable Energy Operated by the Alliance for Sustainable Energy, LLC

This report is available at no cost from the National Renewable Energy Laboratory (NREL) at www.nrel.gov/publications.

\section{Technical Report}

NREL/TP-6A80-66431

July 2016

Contract No. DE-AC36-08GO28308 


\section{NOTICE}

This report was prepared as an account of work sponsored by an agency of the United States government. Neither the United States government nor any agency thereof, nor any of their employees, makes any warranty, express or implied, or assumes any legal liability or responsibility for the accuracy, completeness, or usefulness of any information, apparatus, product, or process disclosed, or represents that its use would not infringe privately owned rights. Reference herein to any specific commercial product, process, or service by trade name, trademark, manufacturer, or otherwise does not necessarily constitute or imply its endorsement, recommendation, or favoring by the United States government or any agency thereof. The views and opinions of authors expressed herein do not necessarily state or reflect those of the United States government or any agency thereof.

This report is available at no cost from the National Renewable Energy Laboratory (NREL) at www.nrel.gov/publications.

Available electronically at SciTech Connect http:/www.osti.gov/scitech

Available for a processing fee to U.S. Department of Energy and its contractors, in paper, from:

U.S. Department of Energy

Office of Scientific and Technical Information

P.O. Box 62

Oak Ridge, TN 37831-0062

OSTI http://www.osti.gov

Phone: 865.576.8401

Fax: 865.576.5728

Email: reports@osti.gov

Available for sale to the public, in paper, from:

U.S. Department of Commerce

National Technical Information Service

5301 Shawnee Road

Alexandria, VA 22312

NTIS http://www.ntis.gov

Phone: 800.553 .6847 or 703.605 .6000

Fax: 703.605.6900

Email: orders@ntis.gov 


\section{Acknowledgments}

This work was funded by the National Renewable Energy Laboratory's Laboratory-Directed Research and Development (LDRD) fund. We wish to thank Stuart Macmillan for his continued support and insights. A special thanks to the team members of the Human-Centered Energy Service LDRD, Steven Isley and Karun Joseph, for their invaluable input. We also wish to thank Bob Fogoros and Tempronics, Inc., for supplying the heated and cooled smart-chairs used in our experiments. We would also like to thank Lucas Phillips and Tom Bethel for their efforts in constructing the environmental test chamber that enabled this research. 


\section{List of Acronyms}

BEMS

HVAC

ML

NREL

PEC

PMP

PPD

PTP
Building Energy Management System

Heating, Ventilation, and Air Conditioning

Machine Learning

National Renewable Energy Laboratory

Personal Environmental Climate

Predicted Mean Vote

Predicted Percent Dissatisfied

Personal Thermal Profile 


\section{Executive Summary}

Although reducing energy use is widely accepted as a critical component of energy and climate change policy in the United States, solutions are non-trivial at least partially because human behavior and decision making related to energy use are extremely complex. For example, U.S. office building energy use is largely driven by air-conditioning demands. However, the optimal temperature setting for each building is not homogenous for all building occupants, leading to the proverbial thermostat war where individuals prefer different temperature settings. Many occupants independently overcome building comfort challenges by using their own space heaters or fans, but these devices create additional energy use and may even compound the issue. These realities about human behavior and preferences contribute to the challenge of reducing energy use in commercial buildings.

The National Renewable Energy Laboratory (NREL) set out to study one component of this problem. Broadly, the building comfort and energy-use reduction challenge can be broken into multiple phases. First, today's understanding of human comfort needs is oversimplified and applied to a general population rather than considering individual preferences. Thus, we developed an experimental process to measure the statistical variability of individuals' comfort requirements. Second, we reviewed personal comfort technologies and found that existing technologies have insufficient controls, lacking the ability, for example, to be controlled remotely by a building's energy management system. On the other hand, automation could help to achieve these products' potential. We established an innovative control system to automate personal comfort products so that they could deliver each occupant's comfort needs. Next, individual devices operating autonomously may satisfy comfort, but to achieve whole-building energy savings, they should be coordinated with the building automation equipment and heating, ventilation, and air conditioning (HVAC) systems. Finally, the localized economic viability of this packaged solution should be confirmed. This report documents NREL's completion of work that addresses phases 1 and 2 using a single personal comfort technology as well as initial work addressing phase 4.

The first personal comfort product NREL tested is a customized office chair that automatically heats and cools the occupant along the seat and chair back according to his or her personal preferences. This product is shown to deliver markedly better comfort at room temperatures well above typical office cooling set points. Experimental subjects reported satisfaction in these elevated air temperatures $\left(27\right.$ to $30^{\circ} \mathrm{C}$, or 80 to $\left.86^{\circ} \mathrm{F}\right)$ at least partly because the chair's cooling effect was tuned to each individual's needs.

Simulation of the chair in office buildings around the United States shows that energy can be saved everywhere, with impacts varying due to the climate. In NREL's study, total building HVAC energy savings for HVAC set point dead-band widening combined with the operation of autonomously operated heated and cooled office chairs exceeds $10 \%$ in hot-dry climate zones. The potential HVAC energy savings increases to $>17 \%$ when hypothetical low-power ( $5 \mathrm{~W}$ ) comfort devices are considered. Due to the high-end nature of the chair considered in this study, the simple payback period for purchasing this product is higher than the expected chair life (eight years) when energy usage alone is considered as opposed to also considering co-benefits such as enhanced productivity of the occupant due to greater comfort. Productivity co-benefits associated 
with enhanced comfort may lower the payback period. However, a productivity study was not conducted as part of this research.

This work led us to establish cost-performance targets for comfort delivery packages. From the population-weighted energy consumption of the tested product, NREL derived several hypothetical energy/cost/comfort targets for personal comfort product systems. In some U.S. climate regions, these show the potential for office building HVAC energy savings in excess of $20 \%$ when the peak power requirements for a thermal comfort delivery package falls below $5 \mathrm{~W}$.

This report documents this research and provides an overview of the methods, results, and areas for future research. 


\section{Table of Contents}

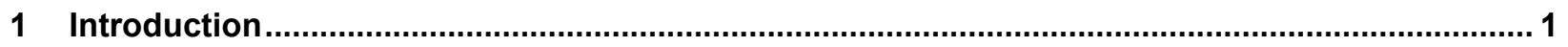

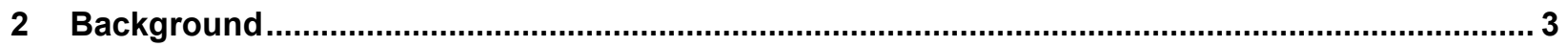

$2.1 \quad$ Early work and the Fanger Model ...................................................................................... 3

2.1.1 Predicted Mean Vote and Predicted Percent Dissatisfied ................................................ 3

2.1.2 Shortcomings of Static Models ............................................................................. 4

2.1.3 Dynamic Environmental Conditions .......................................................................... 5

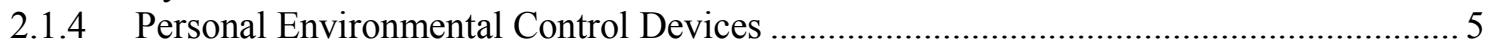

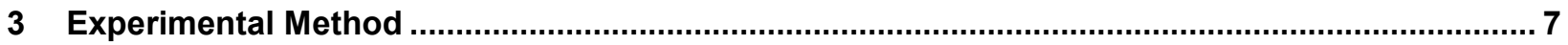

3.1 Hardware, Software, and Experimental Test Facility ……………………………………..... 7

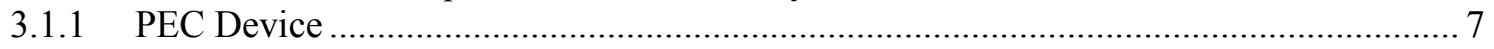

3.1.2 Smart Chair and Automated Microcontroller...…………………………………......

3.1.3 Smartphone to Smart-Chair Interface..................................................................... 7

3.1.4 Environmentally Controlled Chamber (Comfort-Suite) ................................................. 9

3.1.5 Cloud-Based data Acquisition and Control Server ...................................................... 10

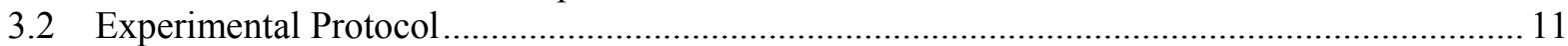

3.2.1 Objective ..................................................................................................... 11

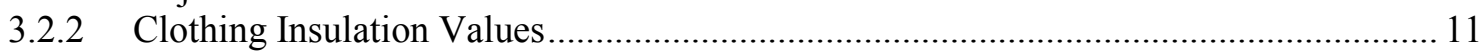

3.2.3 Experimental Phases ......................................................................................... 12

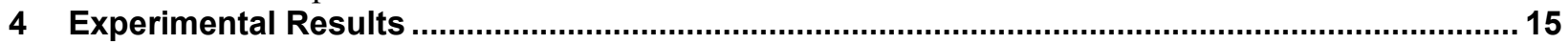

4.1 Thermal Comfort Survey Results.................................................................................. 15

4.2 Personalized Thermal Profile Results ................................................................................... 16

4.3 Averaged Thermal Profile Results ..................................................................................... 17

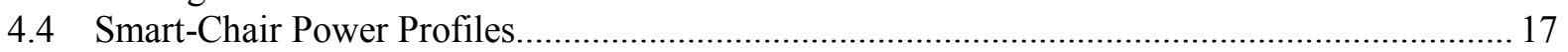

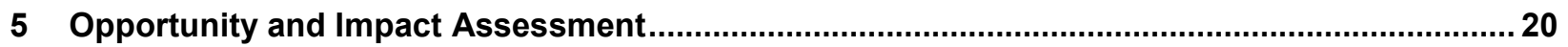

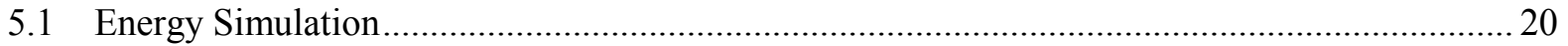

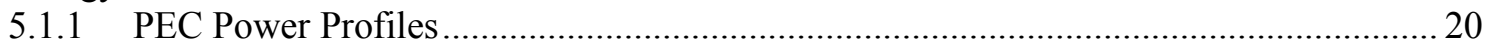

5.1.2 Hypothetical Design Alternatives .........................................................................2. 21

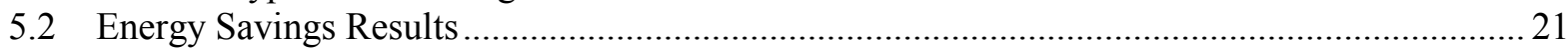

5.3 Criteria for Economic Viability.................................................................................... 23

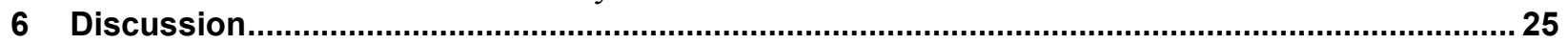

6.1 Individualization of Comfort and Enabling Technologies ......................................................2.25

6.2 Striking a Balance Between Comfort and Energy Efficiency ……………………………….....2 25

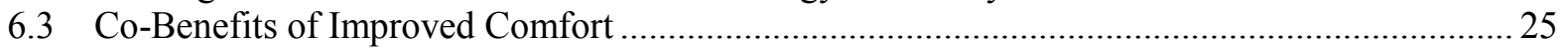

6.4 Expanded Opportunities Beyond Built Environments .............................................................2.25

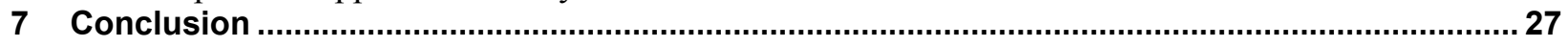

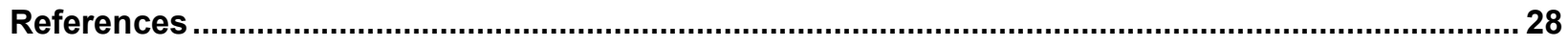




\section{List of Figures}

Figure 1. The percentage of people dissatisfied according to Fanger's models.................................. 4

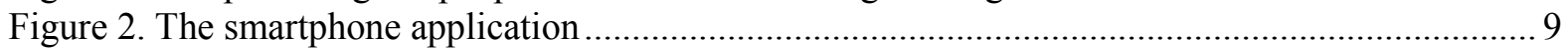

Figure 3. An image of the Comfort-Suite climate-controlled chamber configured as a simulated office

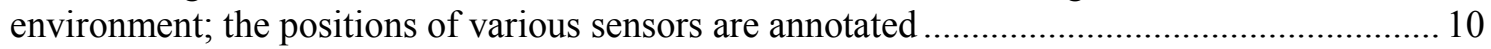

Figure 4. A histogram of the clo values for experimental participants ............................................. 12

Figure 5. Results from Experiments A, B, and C ....................................................................... 13

Figure 6. Thermal sensation (upper panel) and thermal comfort (lower panel) survey responses for 32 individuals showed statistically significant improvement in the comfort evaluation and PMV at dry-bulb temperatures above $27^{\circ} \mathrm{C}$.

Figure 7. Personal thermal profiles for experimental participants ........................................... 17

Figure 8. An example chair power profile.............................................................................. 18

Figure 9. The average chair power profile (blue line) is calculated according to Eq. (1) by projecting the individual PTPs (Figure 7) onto the corresponding chair power surfaces (Figure 8) to arrive at individual power profiles (gray lines)

Figure 10. Personal comfort system power profile.....

Figure 11. Annual HVAC energy savings by climate and building thermostat offset for different PEC power profiles (hypothetical 5W, hypothetical 20W, and as-measured PEC devices [“Actual”]).

Figure 12. HVAC-related energy consumption for the 20-W max PEC power for all climates ......... 23

Figure 13. Energy cost savings due to the personal comfort system............................................... 24

\section{List of Tables}

Table 1. Predicted mean vote Scale

Table 2. Parametric Analysis Details 


\section{Introduction}

The global energy landscape is changing, characterized by increasing penetration of low-carbon resources such as renewable energy and natural gas, along with a simultaneous shift in business and policy objectives that aim to build a more resilient, low-carbon energy future. Reducing energy use is one potential solution contributing toward these goals. As such, understanding the dynamics and determinants of energy use has emerged as an important topic for researchers, practitioners, and policymakers around the world, but it is vastly complex and requires a deep understanding of human preferences and behavior.

Thermal comfort - the condition of mind that expresses satisfaction with the thermal environment and is assessed by subjective evaluation ${ }^{1}$ - is relative, governed by personal factors such as metabolic rate, clothing insulation value, body mass index, activity level, gender, and societal norms. These factors vary widely among individuals and even within individuals as they move through space and time, which makes it difficult to make shared spaces comfortable for all occupants. For example, recent research demonstrated that because men have faster metabolisms on average, women prefer temperatures to be at least a few degrees warmer than men, which biases the standard practice of office air conditioning toward men's comfort today. ${ }^{2}$ Furthermore, humidity, temperature, airflow, radiant temperature, and even its non-uniformity each affect thermal comfort level. Comfort often affects the productivity of individuals, which adds an additional cost or benefit to a firm or household beyond the value of the energy costs accrued. This is especially true in an office environment. As such, there is a tension between achieving reduced energy consumption and maintaining acceptable comfort conditions for building occupants.

In the United States today, office building air-conditioning systems are mostly operated by static controls or schedule-driven building automation systems, and homogenous levels of temperature and lighting are generally applied across space rather than applied heterogeneously to meet differing preferences across occupants. This makes it difficult to achieve universal occupant satisfaction while also achieving energy reductions. In other words, buildings lack real-time feedback on the presence of individual environmental preferences of occupants, limiting the savings potential of energy efficiency measures and creating operational challenges.

Furthermore, operations managers often lack detailed information about actual occupancy and comfort responses, which leads to wasted energy. Not only is this operationally inefficient, but employee complaints of discomfort are widespread, and multiple surveys show that even LEEDcertified buildings generally fail to deliver $80 \%$ or higher occupant satisfaction. ${ }^{3}$ Workers in every climate have been seen to bring in personal comfort devices - space heaters, blankets, fans, etc. - to overcome office comfort dissatisfaction, which ultimately increases building energy use.

Building heating, ventilating, and air conditioning (HVAC) accounts for $15 \%$ of primary energy demand in the United States, and in most climates, it is a major contributor to electric grid peak load. ${ }^{4}$ Recent work indicates that thermostat control in commercial buildings can result in up to $6 \%$ HVAC energy savings per degree Celsius of set point widening $\left(3.3 \% /{ }^{\circ} \mathrm{F}\right) .^{5}$ At the same time, while these improvements are feasible from a technical and engineering perspective, the ways in which humans interact with these systems cannot be ignored. Comfort is a basic human need and is essential for productivity and satisfaction. As the widening of thermostat set points 
can have drastically different impacts on occupants, it can potentially create adverse impacts on comfort if other environmental changes are not also implemented. ${ }^{1,5-7}$

Recent work has aimed to address these challenges. Seeking to improve thermal comfort in buildings, some researchers have developed personal environmental control (PEC) systems that allow occupants individual control of their own local environment through a variety of usercentric devices such as desk fans, leg warmers, wrist warmers, and heated and cooled office chairs. PEC systems also may enable energy use reduction as the provision of comfort at the individual level allows the widening of thermostat set points without adversely affecting comfort levels.

In this research, we perform human subject experiments and building energy simulations to assess the comfort and energy impacts of a heated and cooled office chair with the goal of delivering personalized comfort and maintaining comfort satisfaction when thermostat set points are widened. Personalized environmental control systems offer a unique solution to addressing variations in occupant comfort, especially when dead-band widening scenarios are considered. Through the use of heated and cooled office chairs, desk fans, foot and leg warmers, and other emerging personal comfort technologies, the energy demands that must be met to satisfy personal comfort can be offloaded from a building's HVAC system onto localized comfort devices. The comfort impacts of PEC systems have been investigated in a wide body of previous work, ${ }^{8-12}$ but these studies do not include system-level coordination using devices with two-way communication to enable a) dynamic control and b) coordination between HVAC and PEC operations. This technical report details a technology that NREL has developed and tested to provide localized comfort in office spaces in a way that is amenable to the integration of more advanced control techniques that incorporate information for HVAC and PEC operations as well as human factors. Two-way communication is a requirement for such a system to operate; otherwise, the "right hand" will not know what the "left hand" is doing.

We examine the efficacy of a fully automated and network-enabled PEC system consisting of heated and cooled office chairs for maintaining personal thermal comfort. We also present preliminary analysis of economic and energy impacts this technology can have in different climate regions. While we focus on a single PEC system here, we lay the groundwork for the development of optimization and control algorithms (and human-in-the-loop evaluation thereof) for the entire ensemble of PEC devices that may be incorporated into a building energy management system (BEMS).

Automated control of PEC is one part of the overall energy conservation equation; the other part is reducing total building HVAC energy use. A key component for an effective energyconserving comfort system is its incorporation into an overall building energy management strategy such that energy demands related to comfort can be balanced with HVAC and overall building energy usage. In the past, BEMS had relatively few levers to enhance comfort or reduce costs. However, new PEC systems could result in an enhanced level of control and expand opportunities to include cost savings and comfort improvements. The integration of PEC into a BEMS affords additional options for meeting thermal comfort needs without relying on the HVAC system alone. As such, we use building simulations to analyze the national energy implications of deploying automated PEC in commercial buildings in several climate zones. 


\section{Background}

\subsection{Early work and the Fanger Model}

Since the 1950s, research related to thermal comfort generally has focused on designing indoor environments suitable for a general population. For example, in P.O. Fanger's thermal comfort experiments, surveys assessed the thermal comfort of a large sample group of human subjects in climate-controlled chambers. ${ }^{6,12-18}$ Fanger's early work laid the foundation for thermal comfort research, including development of the Predicted Mean Vote (PMV) and Predicted Percentage of Dissatisfied (PPD) measures. These equations predict human thermal comfort in buildings given a set of parameters that define the indoor environmental conditions as well as human factors. The PMV equation predicts how a group of people perceives the thermal comfort of a room; however, it does not address individual preferences, and it has been argued that unintended biases may have been introduced in the model due to the demographics of the original study group participants upon which the model is based. ${ }^{2}$

\subsubsection{Predicted Mean Vote and Predicted Percent Dissatisfied}

The PMV is an evaluation or "vote" of a room's thermal sensation based on a scale of +3 , which represents feeling hot, to -3 , which represents feeling cold. The PDD predicts the percentage of dissatisfied occupants in a room and is a function of a PMV using the following measured parameters related to the room conditions and occupants:

- Air Temperature (Room Condition)

- Clothing Insulation (Occupant Parameter)

- Metabolic Rate (Occupant Parameter)

- Radiant Temperatures (Room Condition)

- Relative Humidity (Room Condition)

- Room Air Speed (Room Condition).

Table 1 shows the PMV scale values and the sensation descriptor associated with each vote. As the PMV moves away from zero (neutral thermal sensation), the percentage of dissatisfied (PPD) occupants increases. 


\begin{tabular}{ll}
\multicolumn{2}{l}{ Table 1. Predicted } \\
$\begin{array}{ll}\text { Predicted mean } \\
\text { vote }\end{array}$ & Sensation \\
\hline+3 & hot \\
+2 & warm \\
+1 & slightly warm \\
\hline 0 & neutral \\
-1 & slightly cool \\
-2 & cool \\
-3 & cold \\
\hline
\end{tabular}

\subsubsection{Shortcomings of Static Models}

The PMV and PPD have become the standard thermal comfort models to assess thermal comfort for building design. Building thermal comfort design guidelines such as ASHRAE Standard 55 and ISO 7730 recommend buildings remain below a PPD of $20 \%$, which equates to PMV between -0.5 and $+0.5 .{ }^{1,}{ }^{19}$ In other words, thermal environments that feel slightly cool, neutral, or slightly warm are considered acceptable for occupant thermal comfort. It is important to note, however, that a building with environmental parameters that yield a PMV of zero will still have a percentage of occupants who are dissatisfied with the thermal conditions (Figure 1) because the PMV is an average assessment of a group of occupants. This average is part of a distribution that includes both individuals that are too hot and too cold in the same space, and these tails are partly attributable to gender and other individual human differences as well as personal well being, mindset, and personal thermal history.

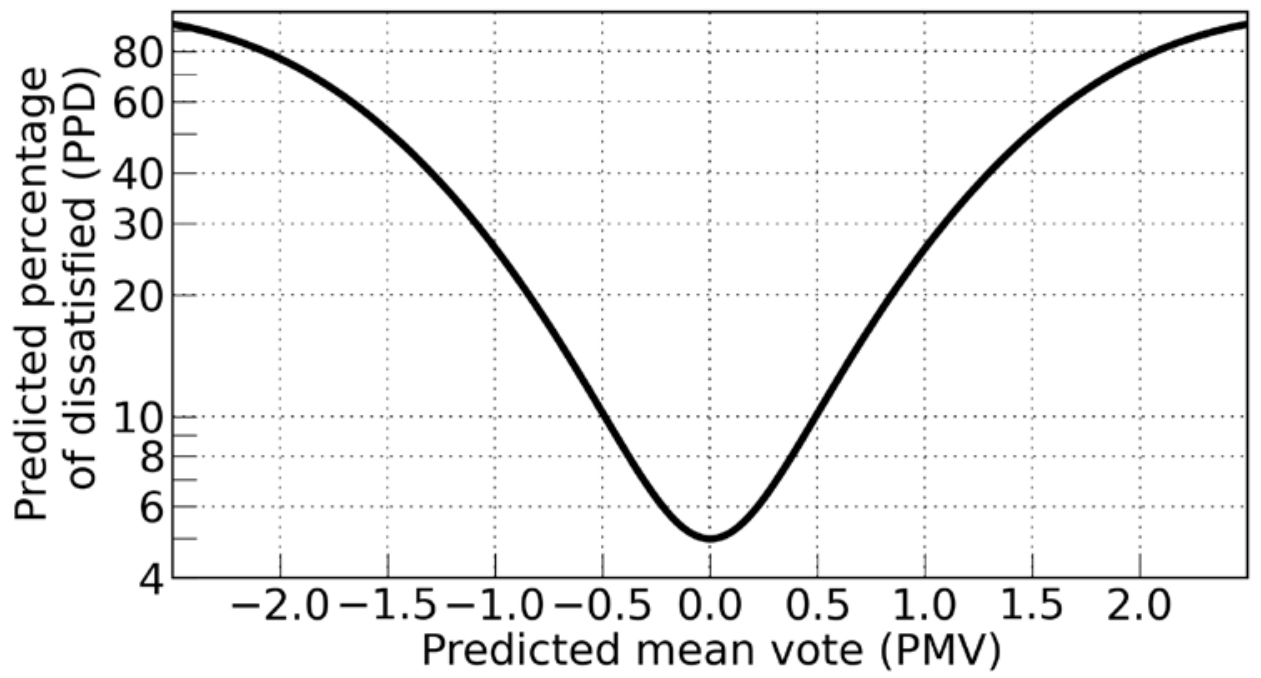

Figure 1. The percentage of people dissatisfied according to Fanger's models

It should be noted that there exists a finite percentage of individuals who are not thermally satisfied at PMV of zero. 
Modeling and predicting thermal comfort can be improved by categorizing occupants based on physiological factors that influence thermal comfort. For instance, consider differences in metabolism between genders, on average, and how this affects preferences for room temperature and differences in thermal perception. Although there is not a significant difference between comfortable "neutral" temperature ranges for males and females, females tend to be more sensitive to temperature deviations from this neutral comfort temperature and more likely to express thermal dissatisfaction. ${ }^{20}$ Furthermore, skin temperatures are linearly correlated with thermal comfort vote, which contributes to predictive models for thermal comfort. ${ }^{21}$ However, improving thermal comfort prediction accuracy of the model is possible by clustering individuals based on personal thermal preferences. ${ }^{21}$ This research demonstrates the importance of integrating individual preference-based environment changes into modeling thermal comfort and its potential for generating energy use savings.

\subsubsection{Dynamic Environmental Conditions}

Building occupants frequently experience changes in room temperatures, or transient thermal conditions, as they travel throughout or enter into buildings during the course of a day. In response, building occupants may modify their thermal environments when they feel discomfort by taking actions such as putting on additional clothing or opening windows. Dynamic thermal conditions and adaptive human behaviors are especially prevalent when building designs incorporate natural ventilation which, in some cases, rely on occupants to adjust windows for cooling comfort. To account for the dynamic thermal nature of buildings and adaptations of occupants, Brager and de Dear (1998) developed the Adaptive Comfort Models. ${ }^{22,23}$ The Adaptive Thermal Comfort Model, developed through analysis of thermal comfort studies, is based on the premise that occupants will naturally adjust or adapt to their environment to maintain thermal comfort. ${ }^{23}$

The array of thermal comfort technologies available to building occupants is expanding rapidly. Further, advances in computational power, wireless communication, and sensing capabilities now allow for real-time analysis, prediction, and modeling of thermal comfort conditions at very fine levels of granularity. ${ }^{24-28}$ The combination of more advanced thermal comfort-enhancing technologies as well as the ability to control them dynamically has opened up new avenues for research about how to intelligibly and efficiently control and model building occupant comfort and building operations.

\subsubsection{Personal Environmental Control Devices}

PEC devices allow individuals to augment their local ambient conditions (i.e., optical, thermal, humidity, ventilation, air movement, and acoustic conditions) to fit their preferences. The concept of fine-grained control of local thermal environments, such as that provided by PECs, is not new (e.g., space heating). However, the ability to integrate and coordinate the operation of numerous localized comfort devices with larger-scale building facilities is a recent development. As such, early research on PEC systems has explored the design principles that are required to maintain human thermal comfort. For example, the University of California - Berkeley's Center for the Built Environment pioneered this area of research with an extensive body of work examining the efficacy of a wide array of PEC systems. Several PEC technologies have been studied including ventilated desk systems, personal table fans, foot warmers, radiant thermal panels, and more recently, heated and cooled office chairs. ${ }^{10,11,29-31}$ PEC systems such as these 
have been shown to improve thermal comfort across room temperatures spanning $16^{\circ} \mathrm{C}$ to $29^{\circ} \mathrm{C}$ $\left(60.8\right.$ to $\left.84.2^{\circ} \mathrm{F}\right)$.

In light of this, modeling thermal responsiveness and sensitivity of different regions of the human body has proven to be useful for developing effective PEC systems. In a series of papers, Zhang et al. (2009) detail the Berkeley Thermal Comfort Model that predicts the thermal sensation and comfort of individual body parts and their influence on the overall body's thermal sensation and comfort. ${ }^{32-34}$ They found that different areas of the human body can be classified into two groups based on their influence on overall thermal sensation:

- Dominant body: The back, chest, and pelvis, which are thermally sensitive locations that can significantly affect the overall body's perception of thermal sensation and comfort.

- Minor body parts: The remaining body parts individually that are thermally less sensitive as compared to the dominant body part. Individually, they may not significantly contribute to the overall body's perception of thermal sensation and comfort. However, a group of minor body parts experiencing thermal discomfort can affect the overall body's perception of thermal sensation and comfort.

The Berkeley model has helped to inform the design of effective PEC systems by identifying the most thermally sensitive body parts. In the case of a heated and cooled office chair, the heat transfer is applied to the back (if reclined) and pelvis while the remaining body parts are exposed to the ambient conditions. The Opposite Sensation Model proposed by Zhang and co-workers (2010) accounts for situations where two or more minor body parts experience the opposite thermal sensation than the dominant body parts. ${ }^{34}$ In these situations, minor body parts can dominate overall thermal sensation. As such, it may be necessary to provide auxiliary thermal conditioning to the hands, face, and legs in order to provide acceptable overall thermal comfort when these minor body parts experience thermally opposite sensations from the dominant body parts. 


\section{Experimental Method}

Leveraging previous research in the field of thermal comfort, we focused on one PEC device that holds promise for being both an effective comfort-enhancing device as well as potentially saving overall building energy use if integrated properly with a BEMS. Experiments were performed with human subjects to assess the efficacy of PEC control for maintaining occupant thermal comfort at elevated and suppressed ambient dry-bulb temperatures. In order to facilitate the experiments discussed in detail below, an array of hardware and software solutions as well as an experimental facility were developed.

\subsection{Hardware, Software, and Experimental Test Facility}

\subsubsection{PEC Device}

The PEC device used in this study was a heated and cooled office chair (manufactured by Tempronics Inc.). The chair had a string of thermoelectric Peltier junctions woven into the seat and back cushions. The direction of current flow through the thermoelectric string determined whether the chair surface provided heating or cooling to the user. The polarity of electricity flowing through the thermoelectric string was controllable. As sold by the manufacturer, a dial allowed the user to manually modulate the chair between full heating to full cooling.

\subsubsection{Smart Chair and Automated Microcontroller}

The chair's manual control was removed and, in its place, a prototype Bluetooth-enabled microcontroller was used. The microcontroller managed local control of the active heating and cooling, collected data, and managed communications with a networked server. Digital temperature sensors for both the seat cushion and underside of the chair were located relatively far from chair cooling fans (for sensing ambient air temperatures). The magnitude of chair heating or cooling was controlled by a pulse-width modulation signal from the microcontroller. As a safety measure, an analog over-temperature shutoff circuit was incorporated to cut power to the smart-chair if the seat temperature exceeded $41^{\circ} \mathrm{C}\left(105.8^{\circ} \mathrm{F}\right)$. Additionally, there was a lower threshold which triggered if the analog temperature signal was lost. Two temperature sensors (low-power linear active thermistor ICs MCP9700) were installed on each smart-chair. One sensor, located on the seat cushion, was utilized as a reference for proportional integral control. The sensor was affixed to the seat cushion upholstery and was positioned immediately above a thermoelectric Peltier junction. Body weight ensured that adequate thermal contact between the sensor and the junction was maintained. The second sensor, located on the underside of the seat, measured the ambient air temperature. Temperature data were collected at a frequency of $2 \mathrm{~Hz}$ and streamed over Bluetooth to an Android smartphone application and finally, forwarded to a data-logging server.

\subsubsection{Smartphone to Smart-Chair Interface}

During the experiments described in Section 3.2, smartphones were provided to participants to facilitate experimental data gathering. The smartphones ran a custom application (Figure 2) that served several purposes:

- Sensor data from the chair were gathered for display and analyzed and forwarded to a central server for logging and analysis. 
- The application received commands from the central server to perform thermal comfort surveys.

- The application sent set point update commands to the smart-chair microcontroller in either of two modes:

- Users updated the smart-chair set point through a slider bar on the smartphone touchscreen (Figure 2, top segment).

- The set point of the chair was automatically updated according to a personal thermal profile (PTP) that was constructed during a self-learning protocol.

\subsubsection{Personal Thermal Profile}

The smart-chair's self-learning protocol provided a data array of ambient air-temperature and smart-chair set point pairs. The temperature/set point pairs defined knot points of a piecewise linear interpolating function. When the smart-chair was operated in autonomous mode, set point temperatures were determined via interpolation within the PTP function. Interpolation was performed on this function using the current ambient air temperature (as reported by the smartchair itself) as the independent variable to arrive at the smart-chair set point temperature. The set point temperature range of the smart-chair spans $25^{\circ} \mathrm{C}$ to $40^{\circ} \mathrm{C}\left(77\right.$ to $\left.104^{\circ} \mathrm{F}\right)$. 


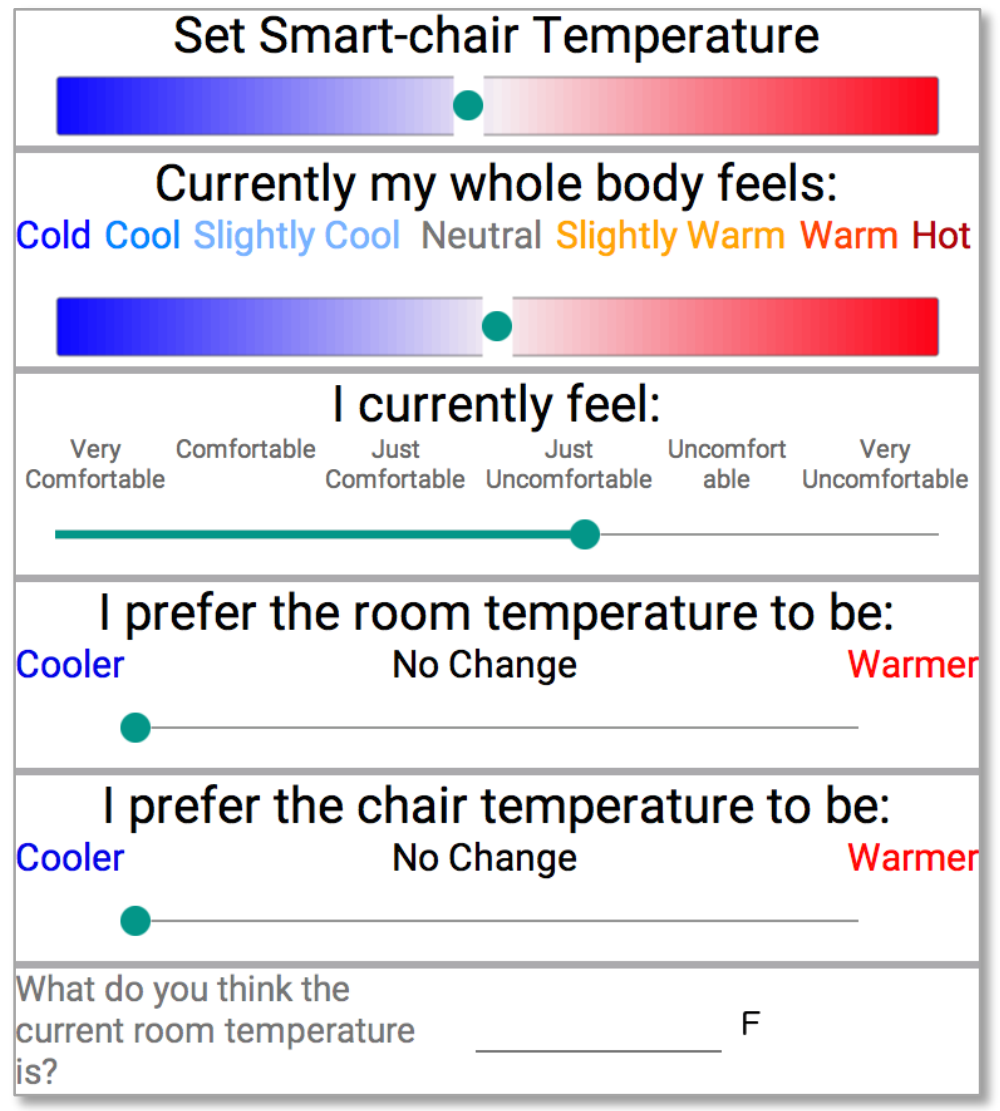

Figure 2. The smartphone application

Slider bars allowed a user to indicate desired smart-chair set point temperature, level of thermal sensation, comfort vote, and thermal preferences for the room and the chair. An input field allowed entry of a current estimate of the room temperature.

\subsubsection{Environmentally Controlled Chamber (Comfort-Suite)}

An occupied environmental test chamber (Comfort-Suite) was constructed to support comfort testing with human subjects (Figure 3 ). The space measured $4.9 \mathrm{~m}$ (length) $\mathrm{x} 2.45 \mathrm{~m}$ (width) $\mathrm{x}$ $2.45 \mathrm{~m}$ (height) and was configured as a simulated office environment. Four $100-\mathrm{cm}-\mathrm{x}-60-\mathrm{cm}$ desks were situated along the long walls of the test chamber with two on each side of the room arranged in a staggered configuration. The walls, floor, and ceiling were wood-framed construction with internal fiberglass insulation and $1.27-\mathrm{cm}$ extruded polystyrene foam. The walls and ceiling were covered with drywall and the flooring was finished with laminate. A once-through cooling and reheating HVAC system with supply registers and vents situated on the floor and ceiling created a uniform flow field within the space (average air velocity at the registers was $2.56 \mathrm{~m} / \mathrm{s}$ and $0.14 \pm 0.03 \mathrm{~m} / \mathrm{s}$ standard deviation on average at the desk locations). While objects and people in the space certainly affected local airflows, the room's high air exchange rate (2.3 $\mathrm{min} /$ air-exchange), coupled with the relatively low average air velocity, are designed to minimize these effects. 
Temperature within the space was controllable to within $\pm 1^{\circ} \mathrm{C}\left( \pm 2^{\circ} \mathrm{F}\right)$. T-type thermocouples housed in aspirated radiative shields had an error of $\pm 0.5^{\circ} \mathrm{C}\left( \pm 0.9^{\circ} \mathrm{F}\right)$ and were positioned at five locations (the four work stations and the center of the ceiling) with aspirated thermocouples. ${ }^{35}$ Analysis of temperature sensor data showed a high degree of temperature uniformity throughout the space $\left(0.6^{\circ} \mathrm{C}\right.$ mean variance). During the experiments, the relative humidity was bounded between $20 \%-55 \%$.

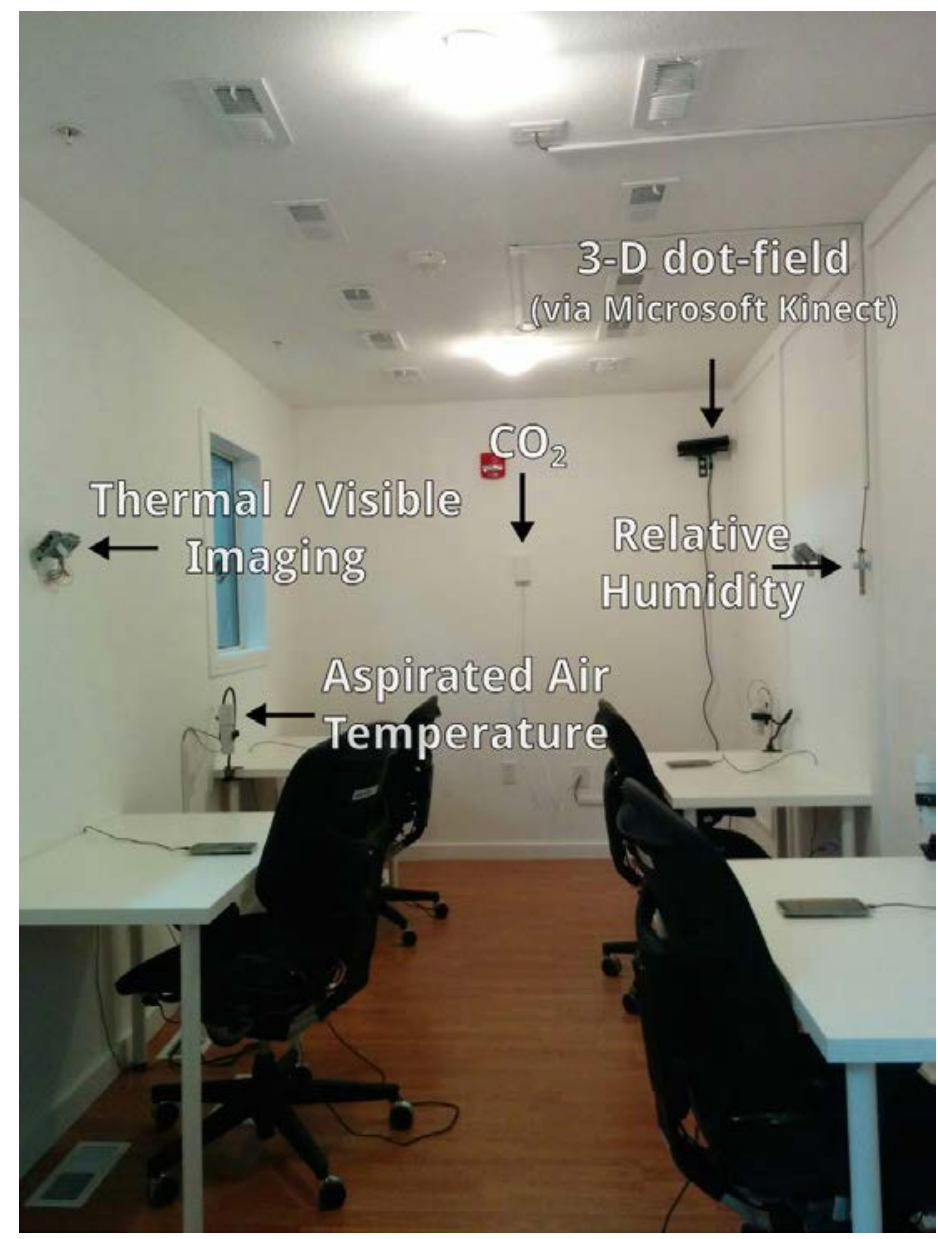

Figure 3. An image of the Comfort-Suite climate-controlled chamber configured as a simulated office environment; the positions of various sensors are annotated

\subsubsection{Comfort-Suite Data Acquisition System}

A data acquisition system (DAQ) controlled the operation of the Comfort-Suite HVAC system. Air dry-bulb temperature, relative humidity, and $\mathrm{CO}_{2}$ concentration data were logged by the DAQ and uploaded to the server at a frequency of $2 \mathrm{~Hz}$.

\subsubsection{Cloud-Based data Acquisition and Control Server}

To orchestrate Comfort-Suite HVAC system operation, the smart-chair operation, and comfort survey administration, a server infrastructure was created to provide a bi-directional data link that allowed for communication to any number of different endpoint devices. These included the 
smartphone application, microcomputers that transmitted imagery data, a Microsoft Kinect device that transmitted human posture data, ${ }^{36}$ and a website information and control dashboard.

\subsubsection{Infrared and Visible Imagery}

At each workstation, infrared (IR) and visible images were taken throughout the experiment. A FLIR Lepton long-ware IR camera module and a four-megapixel camera module was integrated with a Raspberry Pi microcomputer. Images were collected once every three seconds and synced with the server over a Wi-Fi Internet connection. While we did not analyze the imagery in this work, future investigations may examine the accuracy of thermal comfort assessment based on imagery data and potential applications thereof in PEC control system. ${ }^{37,38}$

\subsubsection{Microsoft Kinect}

One Microsoft Kinect device was located high in a corner of the Comfort-Suite. The Kinect was a game system peripheral that allowed players to control a game with their bodies. It utilized an infrared camera and an infrared dot projector to create detailed three-dimensional maps (dotfields) of an environment. The resulting 640-x-480 pixel resolution depth images had 1-mm dot sensitivity. Additionally, the software that powers the Kinect device could produce skeletal tracking data in near-real time for all occupants within the field of view of the device. ${ }^{36}$ These data were uploaded to the server at a frequency of $1 \mathrm{~Hz}$. We also did not analyze the dot-field or skeletal data in this work, but future investigations may focus on predicting occupant discomfort via biomechanical signatures of thermal discomfort (e.g., rubbing forearms, hunching, etc.). Further, recent work by Gao et al. (2013) demonstrated the integration of the Kinect into an occupancy-aware HVAC control system. ${ }^{39}$

\subsubsection{Data Visualization}

Sensor data streams and imagery data were published to a secure website by the server. The website continuously updated a data visualization framework, allowing for experimental data integrity to be verified while experiments are in progress. Additional input fields on the website allowed the temperature set points of both the Comfort-Suite and the smart-chairs to be controlled remotely.

\subsection{Experimental Protocol}

\subsubsection{Objective}

The objectives of the following experiments were threefold. First, we aimed to assess the thermal comfort impact of automated heated and cooled smart-chair operation on individuals in a simulated office environment. Second, we sought to understand how variations in individual thermal preferences affected the energy usage of the smart-chairs. Finally, analysis provided a basis data set for quantifying the opportunities for integrating PECs and energy systems across the national building stock.

\subsubsection{Clothing Insulation Values}

Participants were asked to arrive at the experiment facility dressed in business casual attire. As a result, there was some variation in participant clothing choices. Clothing insulation values (clo, a measure of the thermal insulating properties of the clothing) were estimated using a standardized garment checklist. Participant clo values fell within the range $0.35-0.65$ clo with a mode of 0.55 clo, as shown in Figure 4. One aim of these experiments was to measure the comfort 
impacts of the smart-chair in an office setting, so no corrective actions were undertaken to account for differences in clo values among individuals. The distribution of clo values we observed in these experiments was consistent with typical summertime office worker clo values found in the global thermal comfort database. ${ }^{40} \mathrm{~A}$ study that examines the combined impacts of seasonal clothing ensembles and PEC operations was not part of the scope of this research.

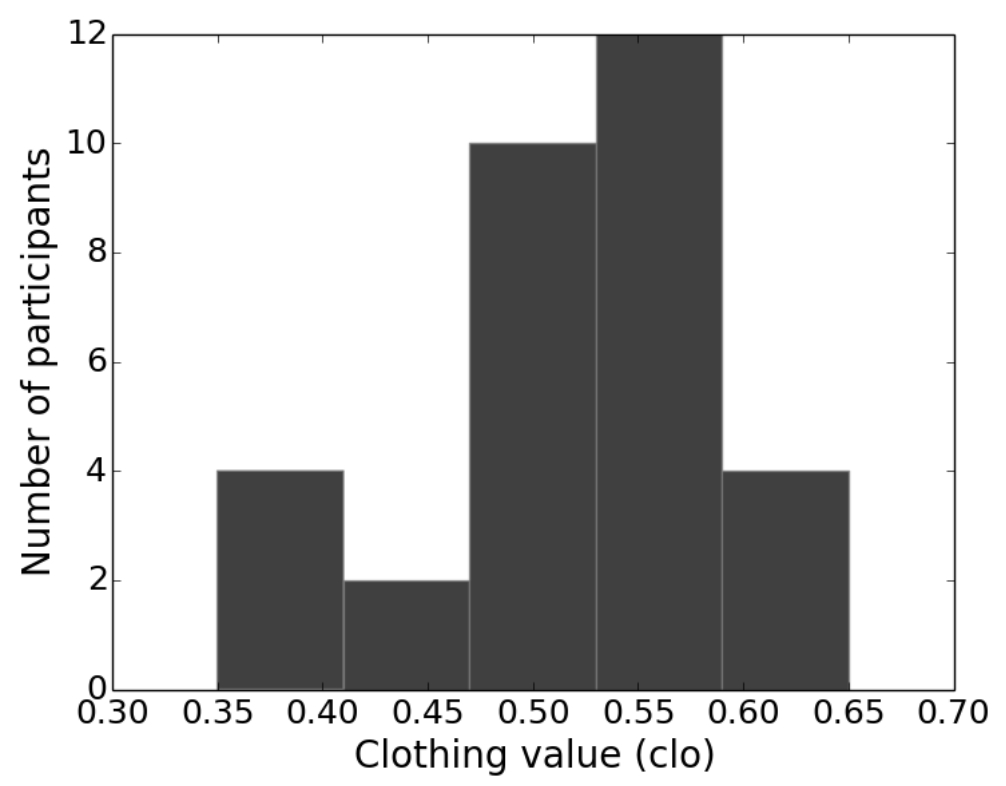

Figure 4. A histogram of the clo values for experimental participants

\subsubsection{Experimental Phases}

Three experiments were conducted with each group of participants. Group sizes varied between two and four people. The temperature within the Comfort-Suite was varied in accordance with the schedule shown in Figure 5. The purposes of each experimental phase are described in the sections below. 


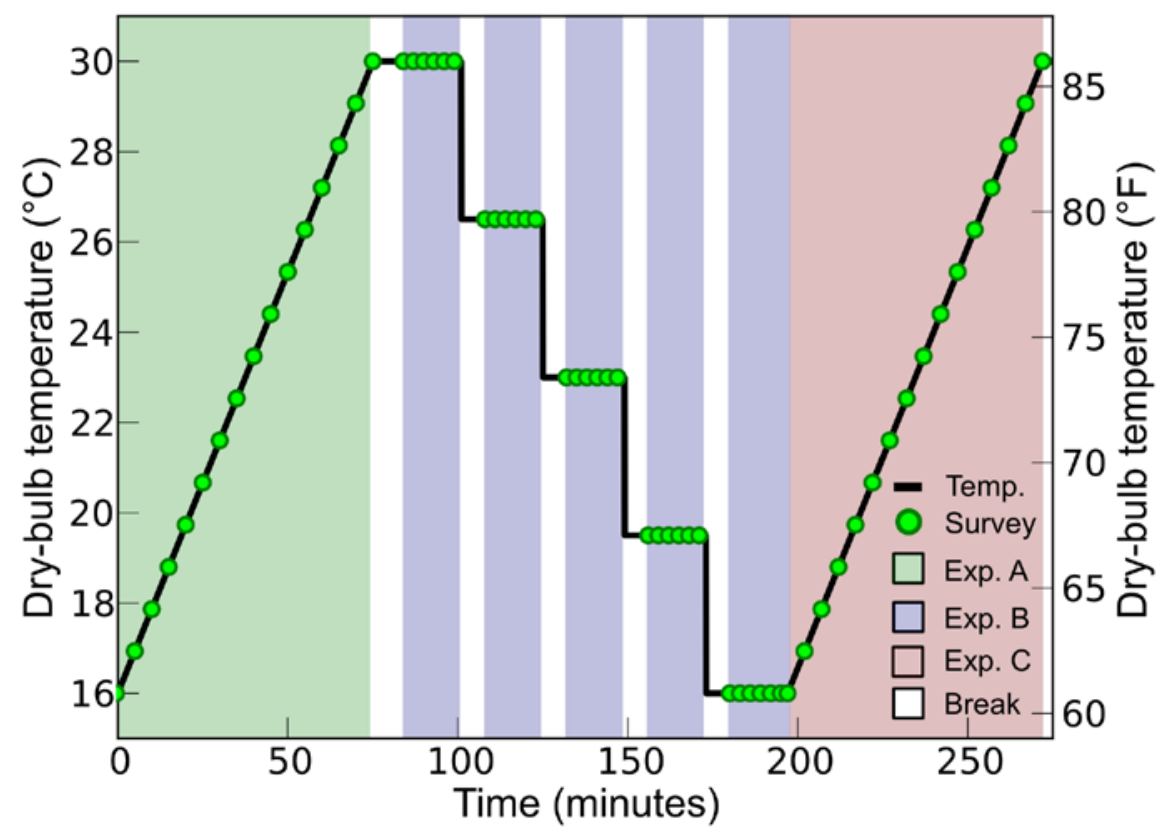

Figure 5. Results from Experiments A, B, and C

The dry-bulb temperature (black line) is ramped at a rate of $0.18^{\circ} \mathrm{C} / \mathrm{min}\left(0.32^{\circ} \mathrm{F} / \mathrm{min}\right)$ from $16^{\circ} \mathrm{C}$ to $30^{\circ} \mathrm{C}(60.8$ to $86^{\circ} \mathrm{F}$ ) during Experiment A (green zone). The dry-bulb temperature is held at five discrete temperatures-30, 27, 23, 19 , and $16^{\circ} \mathrm{C}\left(86,80.6,73.4,66.2\right.$, and $\left.60.8^{\circ} \mathrm{F}\right)$ during the course of Experiment $\mathrm{B}$ (blue zones). The dry-bulb temperature is ramped at a rate of $0.18^{\circ} \mathrm{C} / \mathrm{min}$ from $16^{\circ} \mathrm{C}$ to $30^{\circ} \mathrm{C}$ during Experiment $\mathrm{C}$ (red zone). Comfort surveys (green dots) were conducted every 5 minutes during Experiments A and C, and every 3 minutes during Experiment B.

\subsubsection{Experiment A (Baseline)}

To gather control data for comfort survey responses, a baseline experiment (A) was performed with the smart-chairs deactivated. Participants were situated at workstations within the ComfortSuite. The space was pre-conditioned to a temperature of $16^{\circ} \mathrm{C}\left(60.8^{\circ} \mathrm{F}\right)$. A fifteen-minute thermal adaptation period was observed to allow participants to become accustomed to this starting temperature. During Experiment A, the dry-bulb temperature in the climate chamber was gradually ramped from $16^{\circ} \mathrm{C}$ to $30^{\circ} \mathrm{C}\left(60.8^{\circ}\right.$ to $\left.86^{\circ} \mathrm{F}\right)\left(0.32^{\circ} \mathrm{F} / \mathrm{min}\right)$ over a 75 -minute period at a rate of to $0.18^{\circ} \mathrm{C}$ per minute. Comfort surveys (Figure 2) were given every five minutes to quantify each participant's thermal sensations, thermal comfort, thermal preference, and bestguess estimate of the current ambient temperature. These surveys served as a baseline with which to compare the comfort surveys in later experiments.

\subsubsection{Experiment $B$ (Tuning)}

A second experiment (B) was performed to allow the smart-chairs to self-learn the thermal preference profile of the occupant. The smart-chairs were activated and the temperature set point control was given to participants via the smartphone application. The temperature within the climate chamber was held at $16,19,23,27$, and $30^{\circ} \mathrm{C}\left(86,80.6,73.4,66.2\right.$, and $\left.60.8^{\circ} \mathrm{F}\right)$ for 22 minutes each period. Comfort surveys were given every three minutes for the final 15 minutes of each hold period (i.e., there was a seven-minute thermal adaptation period). The smart-chair set point temperature and ambient air temperature at the end of each hold period were stored in the smartphone application as a knot point in each participant's PTP. 


\subsubsection{Experiment $C$ (Automated Control)}

A final experiment (C) was performed to assess the smart-chair's ability to autonomously provide individualized thermal comfort. As in Experiment A, the ambient temperature of the climate chamber was ramped from $16^{\circ} \mathrm{C}$ to $30^{\circ} \mathrm{C}\left(60.8\right.$ to $\left.86^{\circ} \mathrm{F}\right)$ over a 75 -minute period. The set point of each chair was automatically adjusted by the smart-chair's microcontroller in response to the locally measured ambient room temperature. The set point was determined by referencing each individual's PTP and interpolating between knot points from Experiment B. The smartchair set points were automatically updated at a frequency of $2 \mathrm{~Hz}$. Comfort surveys were administered every five minutes. 


\section{Experimental Results}

In total, 32 individuals participated in these experiments. The ages of participants ranged between 19 and 30 years old (13 female and 19 male). Participants were recruited from universities near the Denver, Colorado metro area. Experiments were conducted between August $10^{\text {th }}, 2015$ and September $20^{\text {th }}, 2015$ at NREL's South Table Mountain Campus.

\subsection{Thermal Comfort Survey Results}

The efficacy of the automated thermoelectric heated and cooled chair affecting individual thermal sensation and comfort was evaluated based on participant responses to the thermal comfort surveys (Figure 2). Figure 6 show that a statistically significant (paired t-test, p-values $<$ 0.05 ) difference in both thermal sensation (top panel, Figure 6) and thermal comfort (bottom panel, Figure 6) was observed at dry-bulb temperatures above $26^{\circ} \mathrm{C}\left(78.8^{\circ} \mathrm{F}\right)$ between the deactivated smart-chair experimental data (gray data) and the autonomously controlled smartchair data (green data). At these elevated temperatures, a 0.5 thermal sensation point shift toward the thermal neutral zone was observed. Similarly, an increase of thermal comfort (by 0.5 PMV) was observed at these temperatures.

Interestingly, smart chair-induced thermal comfort enhancements were not observed at low ambient temperatures. This result differs substantially from previous work by Pasut and colleagues (2012) that found a significant enhancement of thermal comfort at $16^{\circ} \mathrm{C}$ using an identical model thermoelectric chair (albeit with manual temperature controls). ${ }^{41}$ The disagreement likely stems from differences in experimental implementation, the small sample sizes inherent to climate chamber studies, and differences in experimental protocols between the two studies. We do not offer these results as conclusive evidence of no comfort-enhancing effect of the thermoelectric heated and cooled chair at low ambient temperatures, but instead, these results suggest an opportunity for further investigation. 


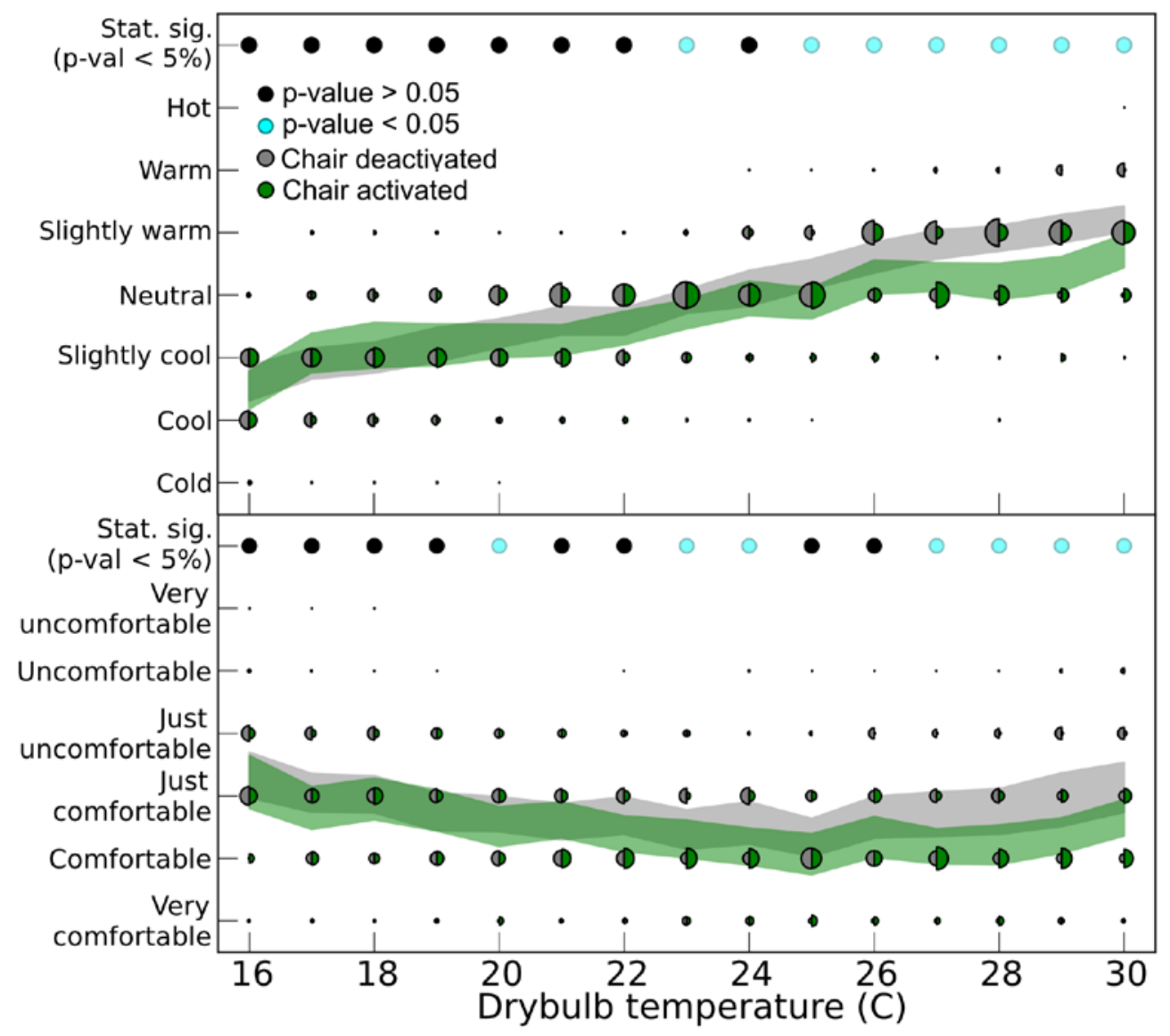

Figure 6. Thermal sensation (upper panel) and thermal comfort (lower panel) survey responses for 32 individuals showed statistically significant improvement in the comfort evaluation and PMV at dry-bulb temperatures above $27^{\circ} \mathrm{C}$

The size of semi-circles for the chair-deactivated (gray) and activated (green) corresponds to the fraction of votes normalized by the total number of votes for a given dry-bulb temperature. The colored bands represent the $95 \%$ confidence interval of the mean votes.

\subsection{Personalized Thermal Profile Results}

PTPs for each participant were created during Experiment B (Figure 7). A participant's PTP informed the smart-chair set point temperature during autonomous operation modes (i.e., Experiment C). Variance in the shape of different individuals' PTPs reflected remarkable differences in thermal preferences among individuals. While several participants preferred for the smart-chair to be relatively warm under all ambient temperatures studied, others preferred that it remain cold. On average, the PTPs monotonically decrease from a set point of $36^{\circ} \mathrm{C}$ at an ambient temperature of $16^{\circ} \mathrm{C}$ to a set point of $28^{\circ} \mathrm{C}$ at an ambient temperature of $30^{\circ} \mathrm{C}$. 


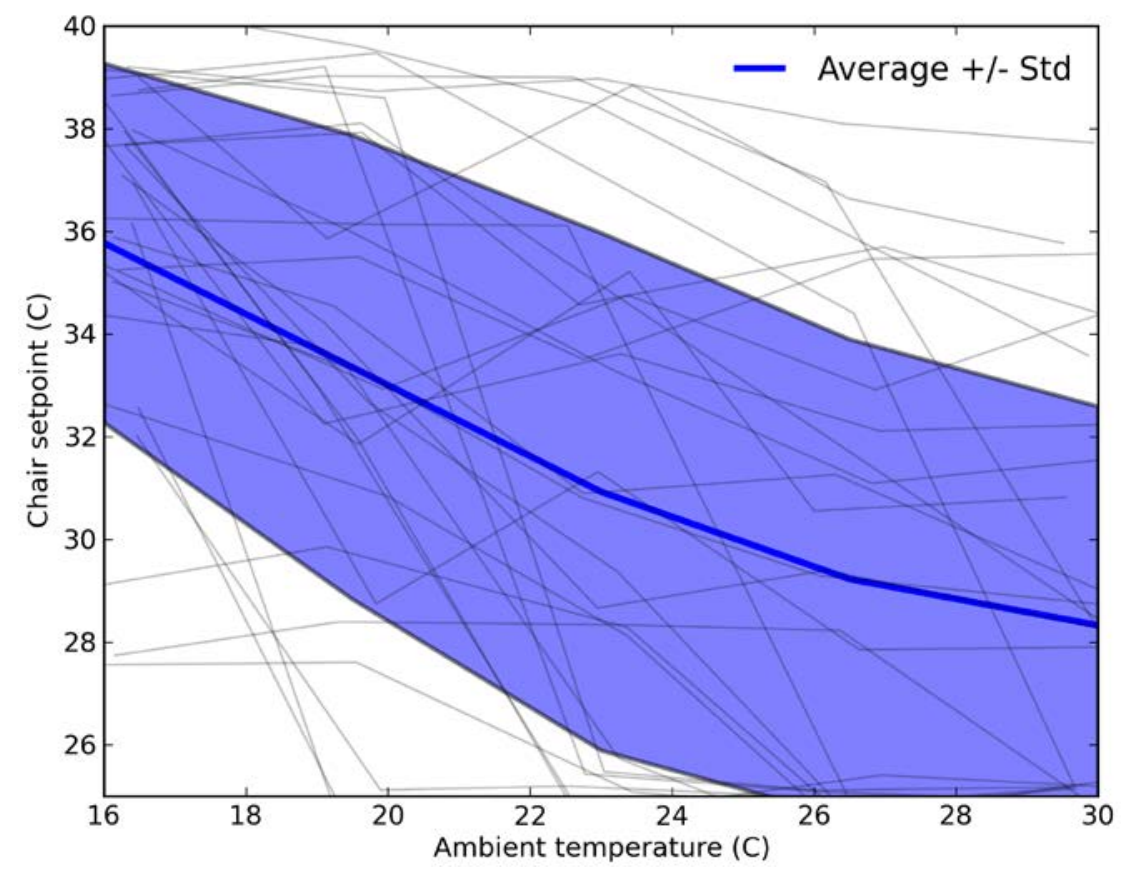

Figure 7. Personal thermal profiles for experimental participants

The individual thermal profiles (gray lines) indicate the participants desired smart-chair temperature set point for a given ambient room temperature. The average thermal profile (blue line) with associated standard deviation margins (blue shaded region) show that, as expected, participants preferred the smart-chair to be relatively warmer at low ambient room temperatures and cooler at relatively high ambient temperatures.

\subsection{Averaged Thermal Profile Results}

The functional shape of an individual's PTP had a direct link to the total energy use of that individual's smart-chair. Smart-chair power depended upon the set point temperature of the chair as well as the ambient temperature of the building (discussed in Section 4.4). When the chair was operated in an autonomous mode, the set point of the chair was determined by local air temperature according to an individual's PTP. As such, if a building's indoor temperature varies throughout the course of a day, so will the power usage of its occupants' smart-chairs.

\subsection{Smart-Chair Power Profiles}

The power required for a smart-chair to maintain a given set point temperature (when occupied by a human body) depended upon the ambient temperature of the room. This relationship was measured for each smart-chair by performing a calibration experiment where the ambient room temperature was varied between $16^{\circ} \mathrm{C}$ and $30^{\circ} \mathrm{C}\left(60.8\right.$ and $\left.86^{\circ} \mathrm{F}\right)$ and the smart-chair set point temperature was varied between $25^{\circ} \mathrm{C}$ and $40^{\circ} \mathrm{C}\left(77\right.$ and $\left.104^{\circ} \mathrm{F}\right)$. An $8 \times 8$ grid of ambient temperature/smart-chair set point temperature pairs was explored. At each set of experimental conditions the smart-chairs were occupied and the temperature of the chair was allowed to equilibrate. Power measurements were collected over a period of 3 minutes at a frequency of $1 \mathrm{~Hz}$. These data were time-averaged and assembled to form a chair power surface (Figure 8) for each chair.

Individual smart-chair power surfaces were collected during a calibration study. An example smart-chair power profile (Figure 8) shows how there was a trough of relatively low power usage 
that spanned from low ambient/low set point conditions to high ambient/high set point conditions. Generally, at the extreme smart-chair set point temperatures of $25^{\circ} \mathrm{C}$ and $40^{\circ} \mathrm{C}(77$ and $104^{\circ} \mathrm{F}$ ), the power required to maintain a given set point was $70 \mathrm{~W}$ and $40 \mathrm{~W}$ respectively, while at mid-range chair set point temperatures $\left(34^{\circ} \mathrm{C} / 93.2^{\circ} \mathrm{F}\right)$ the power reached a minimum near $0 \mathrm{~W}$.

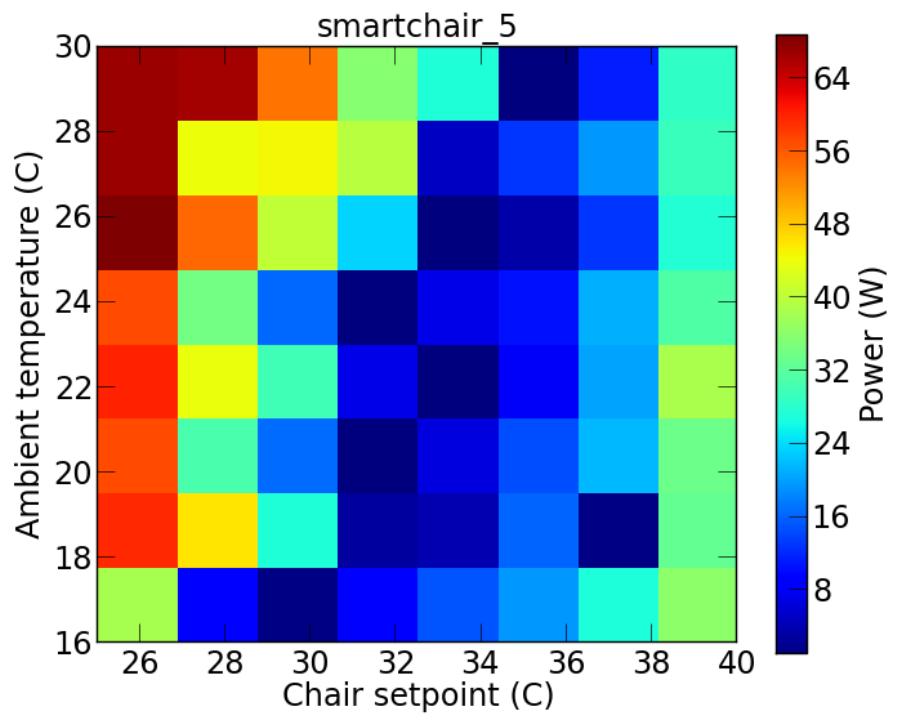

Figure 8. An example chair power profile

Chair power profiles were measured for each of the four smart-chairs used in the experiment. As the ambient temperature decreased, the smart-chair uses less power to maintain the same set point temperature. These data were measured with the smart-chair occupied as the set point temperature and ambient temperature were varied.

The smart-chair power calibration surfaces were useful for modeling the power usage when an individual's PTP determined the chair set point temperature for a given ambient temperature condition. For example, projecting a single PTP (one of the gray lines in Figure 7) onto the calibration surface yielded an individualized power curve (smart-chair power vs. ambient temperature, as shown in Figure 9).

To arrive at the average power usage profile for many individuals (each with a unique PTP), each PTP was projected onto the calibration surface and the average power was calculated according to the following equation:

$$
\bar{P}_{\text {avg }}\left(T_{\text {ambient }}\right)=\frac{\sum_{i}^{N} P_{\text {surf }}^{C(i)}\left(T_{\text {ambient }}, P T P^{i}\left(T_{\text {ambient }}\right)\right)}{N}
$$

where $C(i)$ maps an individual to the smart-chair that he or she occupied, $P_{\text {surf }}^{C(i)}$ is the calibration power surface (see Figure 8) corresponding to the smart-chair that the $i^{\text {th }}$ participant occupied, $T_{\text {ambient }}$ is the ambient temperature of the room, and $\operatorname{PTP}^{i}\left(T_{\text {ambient }}\right)$ is the PTP for the $i^{\text {th }}$ individual, and $N$ is the total number of individuals considered in the average. This aggregation 
and mapping operation takes a collection of PTPs and produces an average power profile (as shown by the blue line in Figure 9) that can be integrated into office building energy usage simulations.

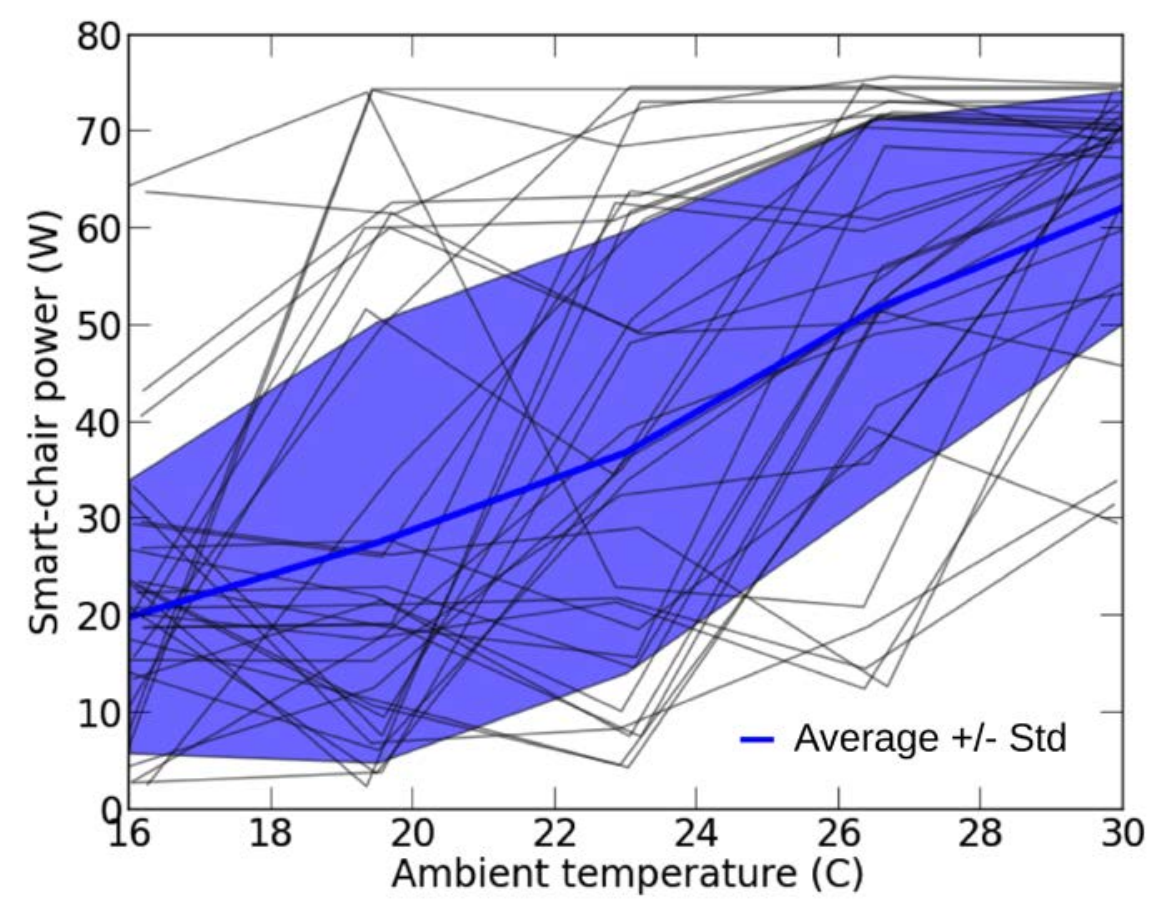

Figure 9. The average chair power profile (blue line) is calculated according to Eq. (1) by projecting the individual PTPs (Figure 7) onto the corresponding chair power surfaces (Figure 8) to arrive at individual power profiles (gray lines)

The aggregate power profile constructed using the actual PTPs measured during the course of the experiments was a monotonically increasing function. This result was counterintuitive, as one would expect the average chair power to reach a minimum that was near "room temperature" (22 $-24^{\circ} \mathrm{C}, 71.6-75.2^{\circ} \mathrm{F}$ ). Indeed, the majority of individual power profiles did show a minimum near moderate ambient temperatures, but the asymmetry of the chair power profiles (approximately $70 \mathrm{~W}$ when cooling and $40 \mathrm{~W}$ when heating) coupled with the large variance in PTPs resulted in a monotonically increasing average chair power with increasing ambient room temperatures.

The average power analysis presented above was useful for predicting the building-level energy impact of a deployed smart-chair-based PEC system. A generalizable approach to analyzing the impacts of PEC systems on energy systems is desirable not only for informing system-scale impacts but also for outlining viable design envelopes for future PEC systems. For example, the heated and cooled smart-chair investigated here was selected from a growing array of existing and emerging PEC technologies, and different technologies could vary substantially in the amount of power they use and the reported comfort levels which they are able to support as ambient room temperatures change. 


\section{Opportunity and Impact Assessment}

\subsection{Energy Simulation}

DOE's OpenStudio software platform, based on EnergyPlus, was used to perform an initial impact analysis of deploying automated PECs in a commercial building in different United States climates. ${ }^{42}$ The parameters for the energy usage profiles of the PEC systems came directly from the experiments performed in the climate chamber. The buildings were DOE small office commercial prototype buildings. ${ }^{43}$ The thermal preference profiles for experiment participants were incorporated into EnergyPlus simulations of a DOE reference small office building for expanded HVAC set points across four representative U.S. climate zones. ${ }^{44}$ These climates span the majority of the commercial buildings in the United States. Parametric analysis was performed by creating a baseline commercial building model and by applying design alternatives to that baseline model.

Table 2. Parametric Analysis Details

\begin{tabular}{|l|l|}
\hline Parameter & Values Simulated \\
\hline Building Type & DOE prototype small office \\
\hline Cooling Set point & $75^{\circ} \mathrm{F}-81^{\circ} \mathrm{F}$ in $1^{\circ} \mathrm{F}$ increments \\
\hline Heating Set point & $64^{\circ} \mathrm{F}-70^{\circ} \mathrm{F}$ in $1^{\circ} \mathrm{F}$ increments \\
\hline Maximum PEC Power & Experimental profile \\
& $20 \mathrm{~W}$ \\
& $5 \mathrm{~W}$ \\
\hline Climate & Phoenix, AZ \\
& Memphis, TN \\
& Baltimore, MD \\
& Chicago, IL \\
\hline Vintage & $1980-2004$ \\
\hline
\end{tabular}

\subsubsection{PEC Power Profiles}

Although the thermoelectric chairs were effectively Peltier heat pumps, we modeled the smartchairs as resistive heaters dissipating an amount of heat that was equal to the average power usage of the smart-chairs, as measured experimentally. This was appropriate for building energyuse calculations since the chairs move heat from people into the indoor air or vice versa, but do not move heat across the thermal enclosure. The only change in the conditioned space was addition of the electrical energy supplied to the chair, which was dissipated as heat within the building. This variable heat load was modeled as a function of indoor temperature based on the population-weighted energy consumption of the PECs in use. The simulated PEC power profiles are shown in Figure 10. 


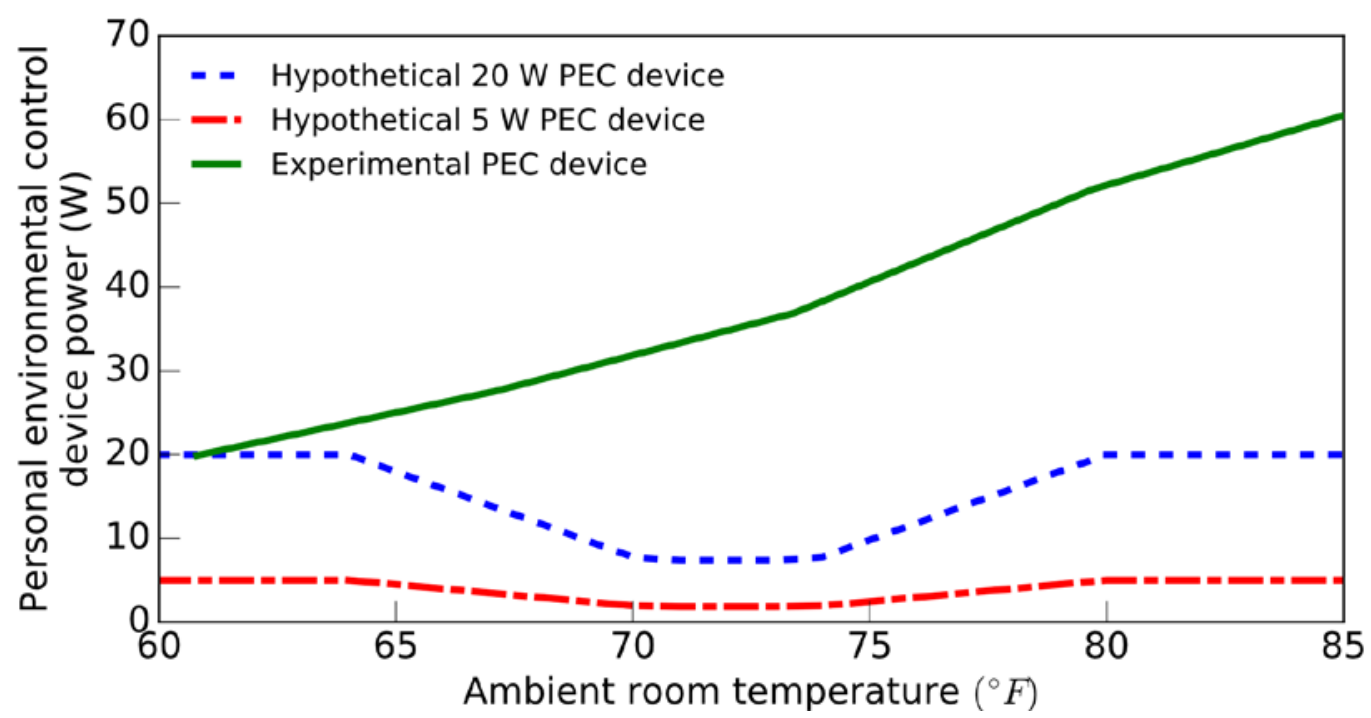

Figure 10. Personal comfort system power profile

Note that this is the average profile over the collection of all systems in the building.

\subsubsection{Hypothetical Design Alternatives}

The parameters considered in this analysis were the power profiles of the PEC, the thermostat set points in the building, and the climate zone. The building details and the range of parameter values are given in Table 2 . The thermostat set points were adjusted in $1^{\circ} \mathrm{F}\left(0.55^{\circ} \mathrm{C}\right)$ increments based on nominal heating and cooling set points of $70^{\circ} \mathrm{F}\left(21.1^{\circ} \mathrm{C}\right)$ and $75^{\circ} \mathrm{F}\left(23.9^{\circ} \mathrm{C}\right)$, respectively. Three power profiles were analyzed as shown in Figure 10. The first profile was the experimentally derived profile from the Tempronics chair. The second two were hypothetical profiles representative of the type of optimized profile averaged across a collection of PECs that could potentially exist within a given building. Below $64^{\circ} \mathrm{F}\left(17.8^{\circ} \mathrm{C}\right)$ and above $80^{\circ} \mathrm{F}\left(26.7^{\circ} \mathrm{C}\right)$, the average system was assumed to be at full power, providing either heating or cooling, respectively. Near $72^{\circ} \mathrm{F}\left(22.2^{\circ} \mathrm{C}\right)$, the average system was assumed to be at minimum power. Note that any individual PEC will go to zero power at some temperature where the occupant is comfortable at that ambient temperature. However, that temperature is expected to vary across a population of occupants such that at any given temperature near where people are comfortable (assumed to be $72^{\circ} \mathrm{F}$ ) some systems will be heating, some will be cooling, and some will be off. Therefore, the average power across the population of PECs will never be zero.

\subsection{Energy Savings Results}

Figure 11 shows a simulated annual HVAC energy savings percentage for each climate, PEC maximum power level, and thermostat set point offset in the parametric study. Negative set point offsets correspond to lowering the building set point during the heating season and positive offsets correspond to increasing the set point during the cooling season. These offsets were calculated relative to the assumed set points of $70^{\circ} \mathrm{F}\left(21.1^{\circ} \mathrm{C}\right)$ for heating and $75^{\circ} \mathrm{F}(23.9 \mathrm{C})$ for cooling. Energy savings were calculated as the reduction in HVAC energy consumption, deriving from lower HVAC load due to thermostat offsets, less the energy use by PECs, which also adds heat to the building air, thus changing HVAC load. Potential for energy savings was found to be quite large even at relatively modest temperature offsets. 
At and near zero offset the average power draw of the collection of as-measured "Actual" PECs was found to be non-zero, so this power draw was added to the building load resulting in negative energy savings. This effect was most pronounced when the smart-chairs were used in cooling mode; however, this effect was still present in heating mode because the PECs were less efficient at heating the building than the primary HVAC system. The experimental, or "Actual," power profile exhibited a more pronounced effect in this regard due to higher power demand than the hypothetical profiles. Even so, simulations using the smart-chair profile showed positive energy savings for all climates if the PEC was able to support occupant comfort when the building thermostat was offset by greater than $+3^{\circ} \mathrm{F}\left(+1.7^{\circ} \mathrm{C}\right)$ for cooling or $-1^{\circ} \mathrm{F}\left(-0.55^{\circ} \mathrm{C}\right)$ for heating.

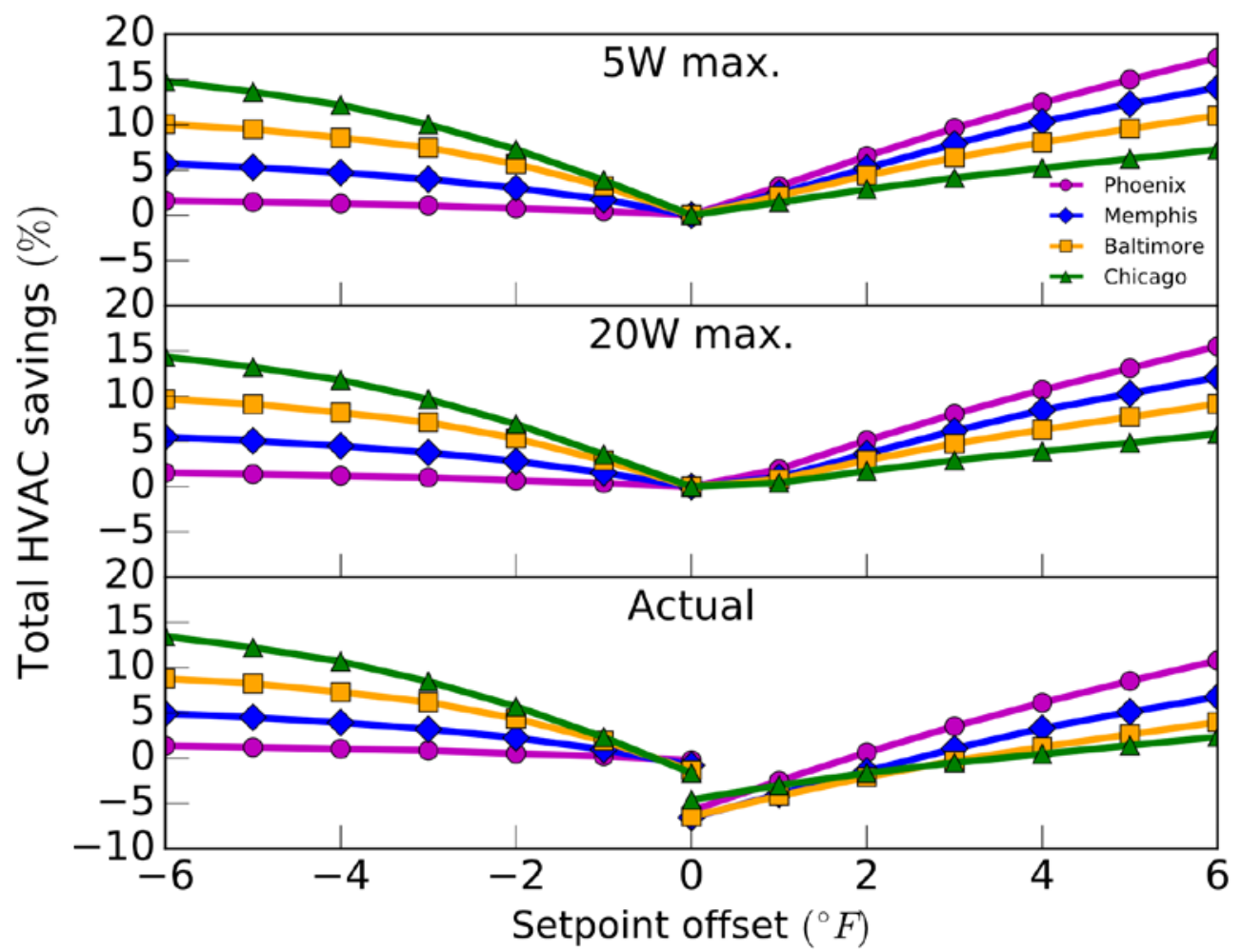

Figure 11. Annual HVAC energy savings by climate and building thermostat offset for different PEC power profiles (hypothetical 5W, hypothetical 20W, and asmeasured PEC devices [“Actual”])

Note that negative energy savings can occur at zero offset because, on average, the collection of PECs never have zero power draw; some people will be cooling at nominal building temperatures while others might turn the PEC off or be heating. Note that benefits derived from increases in individual comfort attained in these situations are not reflected in these charts.

Figure 12 shows a simulated building's energy usage for each climate for the 20-W maximum PEC power profile and $\mathrm{a} \pm 4^{\circ} \mathrm{F}\left( \pm 2.2^{\circ} \mathrm{C}\right)$ thermostat offset. The energy use of the PEC was seen to be a weak function of climate and was small relative to total HVAC energy use. However, the energy savings potential of the combined system was found to be sizeable. 
Standard building controls and set points in the DOE Reference Building Model ${ }^{43}$ were used for this work, except thermostat set point offsets as noted. It should be noted that in some climates there may be a need for alternative HVAC system controls to manage indoor humidity levels for comfort, indoor air quality, and building durability. At set point offsets proposed in this work, it is possible that such dehumidifying equipment could result in additional energy consumption. We leave this as an opportunity for future research.

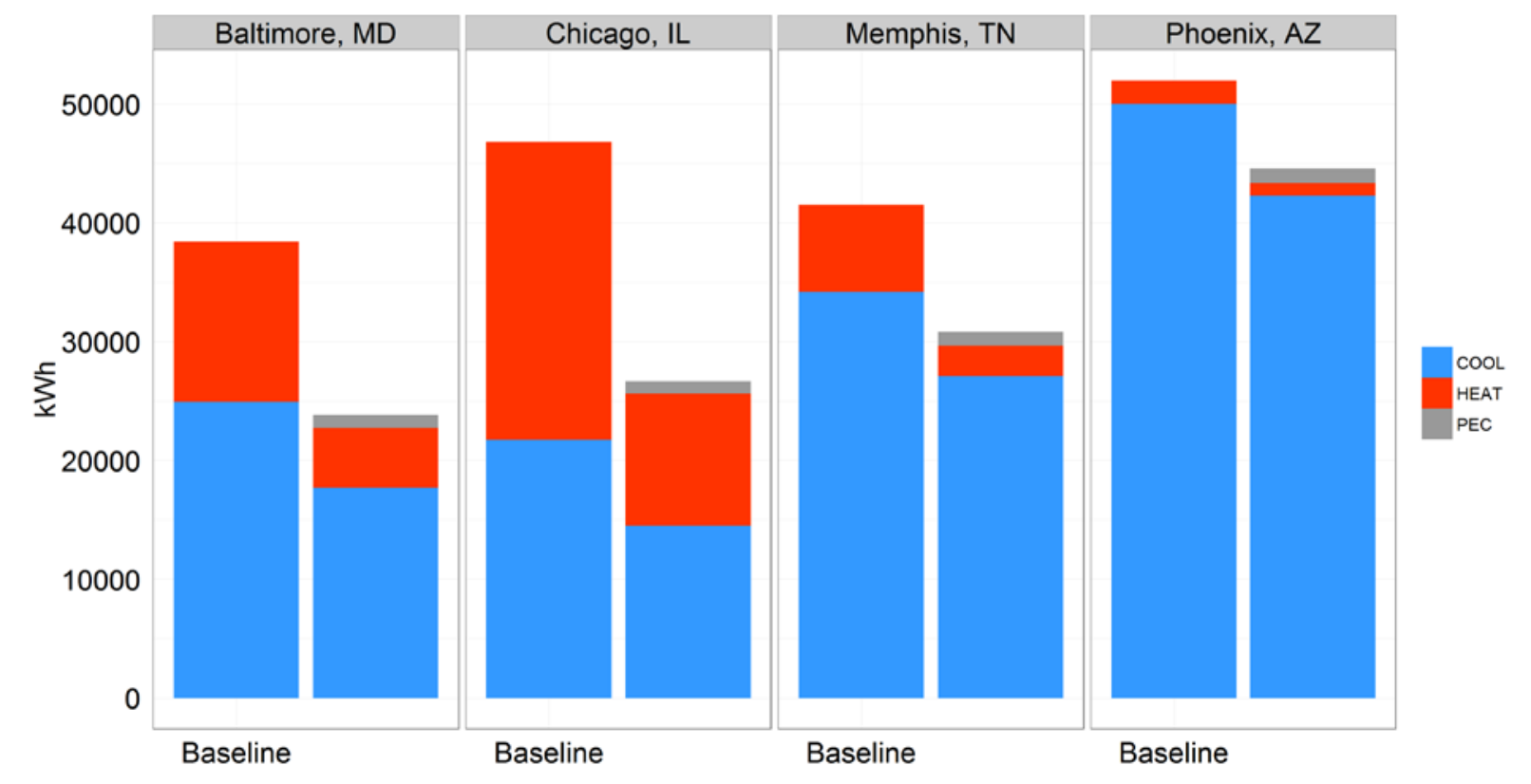

Figure 12. HVAC-related energy consumption for the 20-W max PEC power for all climates

This shows that a relatively small amount of additional energy for the PEC has potential to dramatically reduce HVAC energy use.

\subsection{Criteria for Economic Viability}

Any new technology must be cost-effective to gain market traction. Therefore, the breakeven first cost for each PEC ( $5 \mathrm{~W}$ and $20 \mathrm{~W}$ and the experimental profiles) was estimated across climates assuming an 8-year lifespan. The results are shown in Figure 13. This graph may serve as a guide to developers of new personal comfort systems and to policymakers looking to incentivize market development. For example, if a new system could deliver comfort at a $+4^{\circ} \mathrm{F}$ $\left(+2.2^{\circ} \mathrm{C}\right)$ offset during the cooling season only, the breakeven cost should be between $\$ 50$ and $\$ 200$, depending on climate and power draw. If that device also provides comfort with a $-4^{\circ} \mathrm{F}$ $\left(-2.2^{\circ} \mathrm{C}\right)$ offset during the heating season, the breakeven cost would increase by up to $\$ 45$, depending on climate and power draw. Note that although the energy savings were greater during the heating season, the major economic impact was during the cooling season, thus allowing for a higher cost for the PECs that provide cooling. 


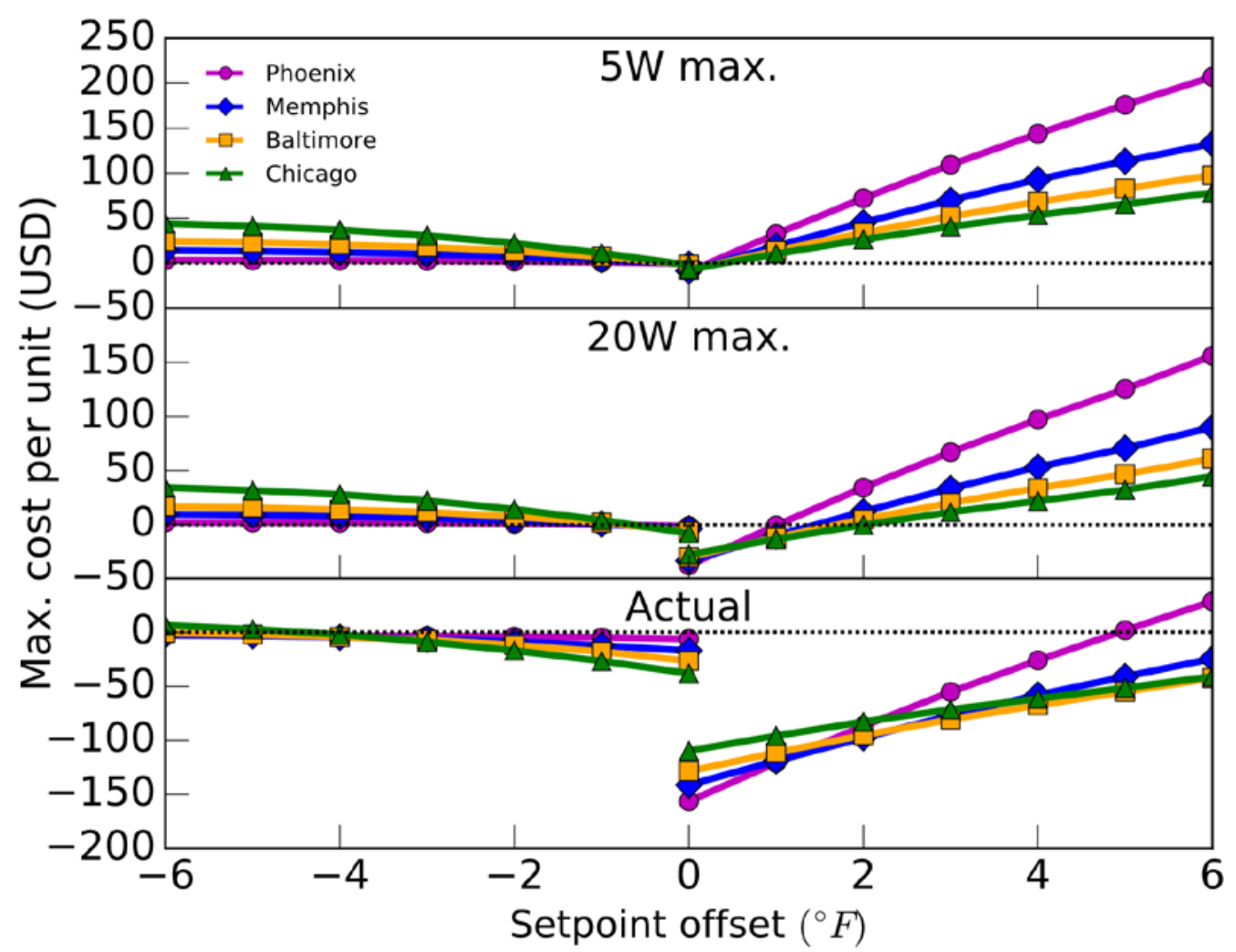

Figure 13. Energy cost savings due to the personal comfort system

Cost savings are dependent upon the device's energy use profile (Figure 10). This provides an estimate of the costs that can be justified for the PEC given the expected cost savings. The black dotted line marks the breakeven point. For clarity, the scale on the lower panel is shifted relative to the two upper panels. 


\section{Discussion}

\subsection{Individualization of Comfort and Enabling Technologies}

In order to deliver improved comfort while enabling reduced energy usage relative to a traditional HVAC approach, a personal comfort system framework must address two key issues. First, the PEC system should enhance thermal comfort when the ambient temperature is operating within a widened margin relative to current standards. Second, the PEC system should deliver such a comfort service while using a low enough amount of power that it becomes economically viable to operate. The automated smart-chair system explored in this work cannot address the thermal comfort of extremities which, in cool ambient conditions, can dominate overall thermal comfort. ${ }^{34}$ The incorporation of auxiliary thermal comfort devices such as hand, wrist, foot, and leg warmers have been shown effective at improving overall thermal comfort. ${ }^{31}$ Incorporation of such auxiliary devices into the automated personal-preference-profile-based comfort system described in this work may lead to greater comfort-energy benefits.

\subsection{Striking a Balance Between Comfort and Energy Efficiency}

Predictive thermo-physiological models such as the IESD-Fiala could provide a means of linking individualized comfort preferences to HVAC and PEC controls. ${ }^{45}$ Models that are incorporated into predictive control schemes that balance thermal comfort requirements with building energy usage allow for a comfort system to anticipate thermal comfort deficiencies or high-energy use events before they occur and minimize the occurrence and magnitude of such events. For example, an intelligent BEMS could anticipate peak load events and choose to pre-heat or -cool an office space beyond the typical dead-band range to save energy. As buildings are often on pricing programs where their peak energy usage determines the electricity rate that they pay to a utility, this strategy could result in monetary savings beyond those gained by consuming less energy. Leveraging thermo-physiological models to predict the comfort impacts of changes due to HVAC set point modifications will allow a BEMS to better utilize automated PEC systems to maintain thermal comfort of building occupants.

\subsection{Co-Benefits of Improved Comfort}

Ambient office temperatures affect worker productivity and performance. For instance, field studies show that, as ambient temperatures exceed $24^{\circ} \mathrm{C}\left(\sim 75^{\circ} \mathrm{F}\right)$ or fall below $20^{\circ} \mathrm{C}\left(68^{\circ} \mathrm{C}\right)$, a decrease in office worker performance is observed. ${ }^{46-50}$ Productivity co-benefits associated with thermal comfort-enhancing PEC systems could further incentivize businesses to deploy them. For example, a 2002 study estimated the potential productivity gains of the office worker populations to be between \$37B and \$208B annually. ${ }^{47}$ Productivity co-benefits associated with thermal comfort create incentives that extend beyond the economic gains associated with a lower overall building energy usage, which is estimated to be $1 \%$ of operating expenses for a nonindustrial workplace. ${ }^{46}$

\subsection{Expanded Opportunities Beyond Built Environments}

The operationalization of personal preference profiles has comfort and energy applications outside of the office as well. Automobiles, buses, airplanes, restaurants, hotels, theaters, and classrooms are all examples of environments that have potential interface points for automated PEC systems. The integration of personal preference profile data, occupancy detection and 
prediction capabilities, and real-time feedback on the energy usage and performance of these disparate energy consuming systems could facilitate more efficient delivery of energy services to individuals. 


\section{Conclusion}

Historically, a lack of information about actual occupancy and comfort responses that reflect individual heterogeneous consumer preferences has led to inefficient energy system operations, yielding significant waste. This creates a tremendous opportunity for energy use reductions through improved occupancy-based controls that achieve significant consumer lighting and HVAC improvements across residential and commercial business types. With the emergence of the so-called "internet of things," devices now have the capability of instantaneous communication with people, buildings, and infrastructure, which open up new research areas in personal comfort and BEMS. "Things" can now collaborate in real-time to provide better quality-of-life services to people while potentially reducing the overall energy and environmental impact of them. In other words, today's technology enables the achievement of multi-objective optimization in the context of reducing energy use while enhancing quality of life by satisfying real-time individual comfort preferences, and it was the objective of this study to explore one such application.

In this work, we investigate the potential for smart-chairs in an office environment to reduce building-wide energy use by meeting individual thermal comfort preferences in real time. This research aimed to demonstrate the value of collecting individual-level data on occupant presence and adaptive behavior for reducing energy use and ultimately, to contribute to the growing need for improved representation of occupants in building energy simulation tools. While this study provides a pilot and demonstrates the potential for gaining a greater understanding of behaviorrelated model inputs, the scope of opportunity is much larger and provides significant room for growth toward developing novel occupant-centered building software and hardware that can be integrated cost effectively with building control schemes. Personal preference profiles that follow people through space and time can be an enormous benefit not only to the people that they are associated with, but also to the intelligent operation of large scale energy systems.

Here we have outlined an integrated approach for evaluating comfort and energy impacts of PEC technologies. Human subject tests were carried out in an environmental test chamber that mimics an office environment. An automated PEC system consisting of a heated and cooled office chair that is automated via a smartphone was evaluated for its ability to enhance personal comfort at ambient temperatures outside of typical HVAC set point ranges. PTPs were measured for each of 32 experimental participants and these profiles were integrated into a series of building energy simulations to assess the energy impacts of such a PEC system deployed in a small office building in the United States. Our results (Figure 6) indicate the autonomously controlled smartchairs are capable of maintaining personal comfort at temperatures as high as $30^{\circ} \mathrm{C}\left(86^{\circ} \mathrm{F}\right)$, which could result in up to a 10\% HVAC energy reduction in hot-dry climates (Figure 11, bottom panel magenta line for Phoenix).

While we focused on a single PEC device, the groundwork has been laid for the characterization of a variety of emerging PEC technologies as well as the design and optimization of building integrated control systems that operate them. The research approach followed in this work sets the stage for further advances in human-informed design of energy-efficient PEC systems and human-in-the-loop development of the algorithms that control them. 


\section{References}

1. ASHRAE Standard 55. 2013. "Thermal environmental conditions for human occupancy." Atlanta. Am. Soc. Heat. Refrig. Air-Cond. Eng. Inc 55.

2. Kingma, B., and W. van Marken Lichtenbelt. 2015. "Energy consumption in buildings and female thermal demand." Nat. Clim. Change advance online publication, (2015).

3. Walker, K. 2015. Indoor environment quality in LEED buildings: Understanding conditions affecting performance. eScholarship. Accessed March 2016, http://escholarship.org/uc/item/13p0k3sx.

4. DOE. 2009. Buildings Energy Data Book. Washington, D.C.: DOE.

5. Hoyt, T., K. Lee, H. Zhang, E. Arens, and T. Webster. 2009. "Energy savings from extended air temperature setpoints and reductions in room air mixing." Int. Conf. Environ. Ergon. Accessed January 2016, http://escholarship.org/uc/item/28x9d7xj.

6. Fanger, P.O. 1970. "Thermal comfort" and "Prediction of human heat tolerance." In Goldman R.F. 1970. Environmental Stress: Individual Human Adaptations. New York, NY: Academic Press.

7. Hoyt, T., E. Arens, and H. Zhang. 2015. "Extending air temperature setpoints: Simulated energy savings and design considerations for new and retrofit buildings." Build. Environ. (88); 89-96.

8. Arens, E., H. Zhang, and W. Pasut. 2011. "Thermal comfort and perceived air quality of a PEC system." Proc. Indoor Air 2011. Accessed February 2016, http://escholarship.org/uc/item/3sv803jx.

9. Bauman, F., G. Carter, A. Baughman, and E. Arens. 1997. "A Field Study of PEM (Personal Environmental Module) Performance in Bank of America's San Francisco Office Buildings." Cent. Built Environ. Accessed December 2015, http://escholarship.org/uc/item/717760bz.

10. Taub, M., H. Zhang, E. Arens, F. Bauman, D. Dickerhoff, M. Fountain, W. Pasut, D. Fannon, Y. Zhai, and M. Pigman. 2015. "The use of footwarmers in offices for thermal comfort and energy savings in winter." eScholarship. Accessed January 2016, http://escholarship.org/uc/item/7vc2q28k.

11. Pasut, W., H. Zhang, E. Arens, and Y. Zhai. 2015. "Energy-efficient comfort with a heated/cooled chair: Results from human subject tests." Build. Environ. 84, 10-21.

12. Fanger, P.O. 2001. "Human requirements in future air-conditioned environments." Int. J. Refrig. 24, 148-153.

13. Fanger, P. 1982. Thermal comfort: analysis and applications in environmental engineering. R.E. Krieger Pub. Co. Accessed April 2016, http://www.worldcat.org/isbn/0898744466. 
14. Fanger, P. O., A.K. Melikov, H. Hanzawa, and J. Ring. 1988. "Air turbulence and sensation of draught." Energy Build 12, 21-39.

15. Fang, L., G. Clausen, and P.O. Fanger. 1988. "Impact of Temperature and Humidity on Perception of Indoor Air Quality During Immediate and Longer Whole-Body Exposures." Indoor Air 8, 276-284.

16. Fang, L., G. Clausen, and P.O. Fanger. 1998. "Impact of Temperature and Humidity on the Perception of Indoor Air Quality.” Indoor Air 8, 80-90.

17. Ole Fanger, P. \& Toftum, J. Extension of the PMV model to non-air-conditioned buildings in warm climates. Energy Build. 34, 533-536 (2002).

18. Fang, L., Wyon, D. P., Clausen, G. \& Fanger, P. O. Impact of indoor air temperature and humidity in an office on perceived air quality, SBS symptoms and performance. Indoor Air 14, 74-81 (2004).

19. ISO 7730: Moderate Thermal Environments - Determination of the PMV and PPD Indices and Specification of the Conditions for Thermal Comfort. (ISO, 1994).

20. Jacquot, C.M.C., L. Schellen, B.R. Kingma, M.A. van Baak, and W.D. van Marken Lichtenbelt. 2014. Influence of thermophysiology on thermal behavior: the essentials of categorization. Physiol. Behav. 128, 180-187.

21. Schellen, L., Loomans, M. G. L. C., de Wit, M. H., Olesen, B. W. \& van Marken Lichtenbelt, W. D. The influence of local effects on thermal sensation under non-uniform environmental conditions--gender differences in thermophysiology, thermal comfort and productivity during convective and radiant cooling. Physiol. Behav. 107, 252-261 (2012).

22. Brager, G. S. \& de Dear, R. J. Thermal adaptation in the built environment: a literature review. Energy Build. 27, 83-96 (1998).

23. de Dear, R. \& Brager, G. S. Developing an adaptive model of thermal comfort and preference. Cent. Built Environ. (1998). at <http://escholarship.org/uc/item/4qq2p9c6>

24. Shaikh, P. H., Nor, N. B. M., Nallagownden, P., Elamvazuthi, I. \& Ibrahim, T. A review on optimized control systems for building energy and comfort management of smart sustainable buildings. Renew. Sustain. Energy Rev. 34, 409-429 (2014).

25. Castilla, M. et al. A comparison of thermal comfort predictive control strategies. Energy Build. 43, 2737-2746 (2011).

26. Castilla, M., Álvarez, J. D., Normey-Rico, J. E. \& Rodríguez, F. Thermal comfort control using a non-linear MPC strategy: A real case of study in a bioclimatic building. J. Process Control 24, 703-713 (2014).

27. Dong, B., Lam, K. P. \& Neuman, C. Integrated building control based on occupant behavior pattern detection and local weather forecasting. (2011). 
28. Ferreira, P. M., Ruano, A. E., Silva, S. \& Conceição, E. Z. E. Neural networks based predictive control for thermal comfort and energy savings in public buildings. Energy Build. 55, 238-251 (2012).

29. Bauman, F., Carter, T. \& Baughman, A. Field study of the impact of a desktop task/ambient conditioning system in office buildings. Cent. Built Environ. (1998). at

$<$ http://escholarship.org/uc/item/8x98n5hj>

30. Tham, K. W. \& Pantelic, J. Performance evaluation of the coupling of a desktop personalized ventilation air terminal device and desk mounted fans. Build. Environ. 45, 1941-1950 (2010).

31. Zhang, H., Arens, E. \& Zhai, Y. A review of the corrective power of personal comfort systems in non-neutral ambient environments. Build. Environ. 91, 15-41 (2015).

32. Zhang, H., Arens, E., Huizenga, C. \& Han, T. Thermal sensation and comfort models for non-uniform and transient environments: Part I: local sensation of individual body parts. Cent. Built Environ. (2009). at <http://escholarship.org/uc/item/3sw061xh>

33. Zhang, H., Arens, E., Huizenga, C. \& Han, T. Thermal sensation and comfort models for non-uniform and transient environments, part II: Local comfort of individual body parts. Build. Environ. 45, 389-398 (2010).

34. Zhang, H., E. Arens, C. Huizenga, and T. Han. "Thermal sensation and comfort models for non-uniform and transient environments, part III: Whole-body sensation and comfort." Build. Environ. 45, 399-410 (2010).

35. Indoor Aspirated Shield. (2013). at $<$ https://buildingsfieldtest.nrel.gov/indoor_aspirated_shield $>$

36. Shotton, J. et al. Real-time Human Pose Recognition in Parts from Single Depth Images. Commun ACM 56, 116-124 (2013).

37. De Oliveira, F., S. Moreau, C. Gehin, and A. Dittmar. 2007. Infrared imaging analysis for thermal comfort assessment. Conf. Proc. Annu. Int. Conf. IEEE Eng. Med. Biol. Soc. IEEE Eng. Med. Biol. Soc. Annu. Conf. 2007, 3373-3376.

38. Burzo, M. et al. Using Infrared Thermography and Biosensors to Detect Thermal Discomfort in a Building's Inhabitants. V06BT07A015 (2014). doi:10.1115/IMECE2014-40269

39. Gao, P. X. \& Keshav, S. SPOT: A Smart Personalized Office Thermal Control System. in Proceedings of the Fourth International Conference on Future Energy Systems 237-246 (ACM, 2013). doi:10.1145/2487166.2487193

40. A global database of thermal comfort field experiments. at $<$ http://www.academia.edu/9529843/A_global_database_of_thermal_comfort_field_experim ents> 
41. Pasut, W. et al. Effect of a heated and cooled office chair on thermal comfort. Proc. 2nd Int. Conf. Build. Energy Environ. (2012). at <http://escholarship.org/uc/item/7dt6v6hn $>$

42. OpenStudio. (Alliance for Sustainable Energy, LLC., 2015).

43. DOE Reference Buildings. (U.S. Department of Energy's Building Technologies Office). at $<\mathrm{http} / /$ /energy.gov/eere/buildings/existing-commercial-reference-buildings-constructed-orafter-1980>

44. EnergyPlus. (U.S. Department of Energy's Building Technologies Office, 2015). at $<$ https://energyplus.net/>

45. Rugh, J. P. et al. Predicting human thermal comfort in a transient nonuniform thermal environment. Eur. J. Appl. Physiol. 92, 721-727 (2004).

46. Fisk, W. J. Health and Productivity Gains from Better Indoor Environments and Their Relationship with Building Energy Efficiency. Annu. Rev. Energy Environ. 25, 537-566 (2000).

47. Seppanen, O., Fisk, W. J. \& Lei, Q. H. Effect of temperature on task performance in office environment. Lawrence Berkeley Natl. Lab. (2006). at $<\mathrm{http} / / /$ scholarship.org/uc/item/45g4n3rv>

48. Tanabe, S., Iwahashi, Y., Tsushima, S. \& Nishihara, N. Thermal comfort and productivity in offices under mandatory electricity savings after the Great East Japan earthquake. Archit. Sci. Rev. 56, 4-13 (2013).

49. Clements-Croome, D. J. in Innovative Developments in Architecture, Engineering and Contruction (ed. Anumba, C. J.) 335-341 (Millpress Science Publishers, 2003). at $<$ http://centaur.reading.ac.uk/11878/>

50. Relationships between the indoor environment and productivity: A literature review ProQuest. at $<$ http://search.proquest.com/openview/297438cd9725b868fbfa68423df67add/1?pqorigsite $=$ gscholar $>$ 